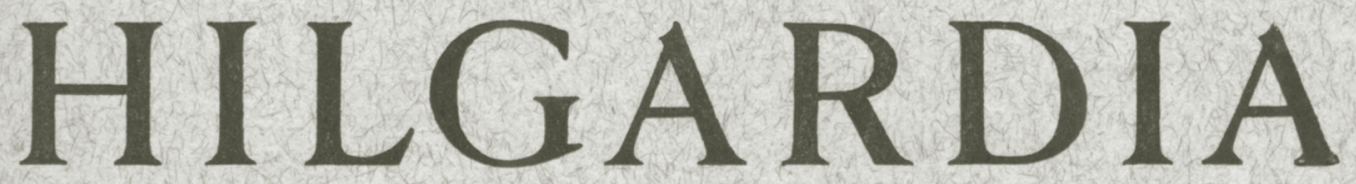

A Journal of Agricultural Science Published by the California Agricultural Experiment Station

\title{
EFFECT OF INSECT NUMBERS ON APHID TRANSMISSION OF POTATO LEAFROLL VIRUS
}

ONKAR SINGH BINDRA

and

EDWARD S. SYLVESTER

UNIVERSITY OF CALIFORNIA - BERKELEY, CALIFORNIA 


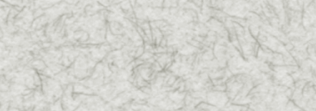

(x) $x+2 x-3$ 


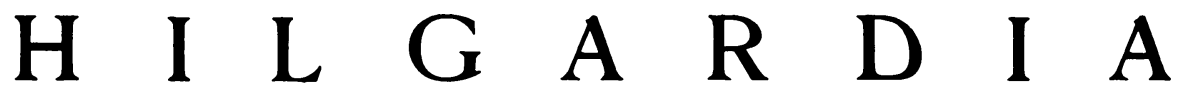

A Journal of Agricultural Science Published by

the California Agricultural Experiment Station

VoL. 31

NOVEMBER, 1961

No. 8

\section{EFFECT OF INSECT NUMBERS ON APHID TRANSMISSION OF POTATO LEAFROLL VIRUS ${ }^{1,}$}

\section{ONKAR SINGH BINDRA ${ }^{3}$ and EDWARD S. SYLVESTER 4}

\section{INTRODUCTION}

IT IS GENERALLY agreed that inoculations by individuals of a group of vectors are separate and independent events, and that virus transmission efficiency by groups of insects will follow that predicted by probabilities generated by expansion of the binomial theorem (Watson, 1936; Storey, 1938; Watson and Roberts, 1939; Posnette and Robertson, 1950; Storey and Ryland, 1955; Sylvester, 1955, 1956).5 However, Kirkpatrick and Ross (1952) reported that in the transmission of potato leafroll virus by Myzus persicae (Sulz.) to Physalis angulata the rate of successful inoculation by groups was lower than expected on the basis of this hypothesis, and that the efficiency of individuals in a group decreased as the size of the group was increased. They considered that this could be due to one or more of the following: (1) the presence of immune or highly resistant plants in the test plant population which would not become systemically infected in spite of the presence of relatively large numbers of vectors per plant and relatively long inoculation access periods; (2) interference of aphids with one another which could prevent feeding by any one of them for a period long enough for transmission of this virus; and (3) aphids feeding for relatively long periods tended to cause the test plants to become more resistant to systemic infection by this virus. A fourth hypothesis (4) might be added, viz., that such observations are due to chance variation. In the following work, tests were designed in an attempt to specifically test each of these four hypotheses.

Williams and Ross (1957) stated that their data suggested that the susceptibility of Physalis angulata was decreased by aphid feeding, but that this effect was not great enough to explain entirely the relative inefficiency of individuals in a colony. However, in both this and the original work (Kirk-

${ }^{1}$ Submitted for publication February 22, 1961.

2 Based upon a thesis submitted by the senior author in partial fulfillment of the requirements for the Ph.D. degree, University of California, Berkeley.

${ }^{8}$ Rockefeller Foundation Research Fellow, Department of Entomology and Parasitology, University of California, Berkeley, 1958-1961. Present address is Agricultural Research Institute, Gwalior, India.

* Entomologist, Department of Entomology and Parasitology, University of California, Berkeley.

s See "Literature Cited" for citations referred to in the text by author and date. 
patrick and Ross, 1952) no experiments were designed specifically to test each of the three proposed hypotheses, and the evidence presented to support their conclusions was not convincing.

Furthermore, in one of the two series of experiments of Williams (1957, unpublished thesis) the results were opposite to those of Kirkpatrick and Ross (1952) : "At a test feeding period of 120 hours, the value of $p$ (efficiency of transmission by individual aphids) increased as the number of aphids was increased; the number of plants infected when 5 and 10 aphids were used was slightly greater than expected." Moreover, in recent works with a nonpersistent (Sylvester, 1955), a semipersistent (Sylvester, 1956), and a persistent (Storey and Ryland, 1955) aphid-borne virus the actual values of transmission were in agreement with expected ones. The present work was taken up to investigate further the influence of insect numbers in aphid transmission of potato leafroll virus, and to try to test the validity of the four hypotheses mentioned above.

\section{REVIEW OF LITERATURE}

The literature on insect transmission of plant viruses includes many studies (Jensen et al., 1952; Pontis Videla, 1953; Semal, 1955; Sheffield, 1957; Stubbs, 1952; Watson, 1946; et cetera) in which small and large groups of vectors have been used, but single insects were not used, and an evaluation of the influence of insect numbers in these reports is difficult. In other works (Laird and Dickson, 1959; Severin and Tompkins, 1950; Skotland, 1953; and many cited by Sylvester in 1954) single insects and groups of varying sizes were used, but in these the experiments were not comparatively designed and cannot be properly assessed. Nevertheless, as expected in all cases there was an increase in percentage infection as the number of insects used was increased; as has also been noted in some field studies (Waggoner and Kring, 1956; Watson et al., 1951; et cetera), and in many cases, good transmission was obtained with groups of insects while none or few transmissions resulted when single insects were used. This has, in the past, led to the suggestion of "mass-action," implying that each insect may inject a subminimal dose into the plant and that several of these doses, which individually are incapable of causing infection, may combine within the plant tissues and cause infection (Carsner and Lackey, 1929). Severin (1931) supported a mass-action hypothesis in transmission of sugar beet curly top virus by Circulifer tennellus (Baker), but the evidence was not conclusive as was pointed out by Giddings (1946) who, working with the same virus and vector, presented additional evidence for the mass-action effect. However, the latter's concept of massaction differed from that noted above, in that his evidence related to the effect of single doses of virus at different strengths. Lastly, Carter and Schmidt (1935) in the studies on mealybug wilt of pineapple were unable to separate mass-action effect from that of probabilities of incidence of toxic individuals. Thus, there is no real evidence for the mass-action hypothesis.

On the other hand, strong evidence has been presented against this hypothesis in transmission by Myzus persicae of Hyoscyamus virus 3 (Watson, 1936), cucumber virus 1 (Watson and Roberts, 1939), and sugar beet mosaic (Severin and Drake, 1948), transmission of maize streak virus by Cicadulina 
mbila Naude (Storey, 1938), and of swollen shoot disease of cacao by Pseudococcus njalensis Laing (Posnette and Robertson, 1950).

Watson (1936) demonstrated that the probability of infection in using a group of insects was the probability that the group contained one or more individuals which alone could cause infection, and she adapted the binomial theorem to her data. Thus, if for single insects $p$ be the probability of infection, and $q$ the probability of noninfection, then $q=1-p$, and the probability of infection by $\mathrm{n}$ insects, $p_{\mathrm{n}}$ equals $1-q^{\mathrm{n}}$. Watson (1936), Storey (1938), and Watson and Roberts (1939) found that the actual values of transmission were in agreement with those calculated by using the binomial theorem and the maximum likelihood estimator; and presented this as a strong evidence for the hypothesis that infections by individuals in a group are separate and independent events. In other words a group will transmit if at least one of its members would have transmitted alone; and the group will not transmit if none would have transmitted when alone. Accordingly, subinfective doses of virus, if inoculated at different foci into a plant, would not combine to give an infective dose. This hypothesis of independence has been subsequently supported by works on sugar beet mosaic (Kvičala, 1947), lettuce mosaic (Sylvester, 1955), cabbage black ringspot (Hamyln, 1953), sugar beet yellows (Sylvester, 1956), and groundnut rosette (Storey and Ryland, 1955) viruses transmitted by the green peach aphid, Myzus persicae (Sulz.).

There are other works on insect transmission of plant viruses in which varying numbers of insects were used in comparatively designed experiments but no conclusions were drawn to support or deny the independence hypothesis. However, an analysis of the data presented in these shows that actual values of transmission by groups of insects were generally in agreement with those expected on the basis of this hypothesis in case of aphid transmission of potato virus $\mathrm{Y}$ (Bawden and Kassanis, 1946), and cucumber mosaic virus (Hoggan, 1933); whitefly transmission of Abutilon virus 1 Baur (Orlando and Silberschmidt, 1946); and beetle transmission of squash mosaic (Freitag, 1956). Thus, the hypothesis of independence of infections by individuals in a group of vectors is now generally accepted.

In the transmission of potato leafroll virus Elze (1927) used single insects and groups of varying sizes, but his conclusion that "With aphids the number of insects used is not of much importance," is of no significance because he may have been working with some other virus or there may have been contamination by aphids as he reported transmission of leafroll by insect species which have since been shown to be nonvectors. Smith (1929) compared groups of 2, 6, 12, and 18 Myzus persicae in transmission of leafroll using only six plants for each group. The data are too meager to draw any conclusion but they do indicate absence of mass-action effect.

In some works on insect transmission of plant viruses, for instance, aphid transmission of cauliflower mosaic (Kvičala, 1948), tristeza virus (Costa and Grant, 1951), and radish yellows virus (Duffus, 1960); and whitefly transmission of Euphorbia prunifolia mosaic (Costa and Bennett, 1950), and Bhendi (okra) yellow vein mosaic (Varma, 1952) the actual values of transmission by groups of insects were frequently less than those expected on the basis of the independence hypothesis, although this has not been brought out 
by the authors. The size of the experiments was, however, small and the results are more indicative than conclusive.

Nevertheless, Kirkpatrick and Ross (1952) in connection with potato leafroll virus reported that "On $P$. angulata, the probability of infection by a group of insects during a six-day feeding period was consistently less than the probability that the colony contained at least one insect capable of causing infection if alone." Williams and Ross (1957) stated in their abstract that "The previous report that the probability that a single aphid ( $M$. persicae) can effect transmission of leafroll virus decreased as the number of aphids per plant is increased is confirmed," although in one of the two series of experiments of Williams (1957, unpublished thesis), on which this abstract was presumably based, the results were just the opposite, as already mentioned in the introduction. Sylvester (1955) in his studies on lettuce mosaic obtained no evidence in support of the hypothesis that increasing the number of insects reduces the susceptibility of the test plant. Again, Sylvester (1956) in his experiments designed to determine the influence of numbers of inoculative aphids on the probability of transmission, in case of sugar beet yellows and Myzus persicae, found that when a design was limited to testing inoculative groups alone, the probability of transmission by individuals was constant, that is, it did not decrease as the number of vectors was increased.

Kirkpatrick and Ross (1952) reported that Myzus persicae individuals feeding alone infected more plants with leafroll than did similar ones that fed together with 5 or 10 noninoculative aphids. They interpreted their data as indicating that aphid feeding causes changes in plants that make them resistant to systemic infection. Sylvester (1956) tested inoculative and noninoculative aphids in different combinations in a factorial-designed experiment and found that under these conditions the probability of infection tended not to be constant, but reported that the changes in this probability could not be associated with noninoculative members of the test groups. Williams and Ross (1957) have since presented evidence for 'reduction in susceptibility' of Physalis angulata to infection of leafroll by $M$. persicae (suggested by Kirkpatrick and Ross in 1952) as a result of feeding of large numbers of noninoculative $M$. persicae for prolonged periods. They did not consider this effect to be great enough to explain entirely the relative inefficiency of individuals in a colony. However, no experiments designed to test whether aphid feeding is a factor responsible for lower transmission by individuals in a group than when alone have been published or included in Williams' unpublished thesis (1957).

Simpson and Shands (1949) did not present any data but reported that "Experimental evidence indicates that eventually the potato plant reaches a condition, physiologically, beyond which it can no longer become infected or if so, only with difficulty." They further considered that this point could probably be reached because of lack of moisture, because of direct aphid damage, or simply because of the plant reaching the end of its growing period. However, besides these two references there appears to be no report on the deleterious effect of insect feeding on virus transmission and a verification of these reports appears necessary. 


\section{MATERIALS AND METHODS}

Potato tubers infected with leafroll virus were obtained from the Department of Plant Pathology, University of California, Berkeley. These were taken out of a field collection from the Tulelake area of California. The identity of the virus was established by inoculating with Myzus persicae, plants of Datura stramonium L., Physalis angulata L. and P. floridana Rydb. grown from seed, and comparing the symptoms produced with those reported in the literature (Hovey and Bonde, 1948; Kirkpatrick, 1948; MacCarthy, 1954). Confirmation was obtained in serial transmission studies (see page 288), which showed that the virus was persistent in its vector. There is no other virus in potatoes which is known to be persistent in its aphid vector.

The insects used have been maintained in eages in the glasshouse of the Department of Entomology and Parasitology, University of California, Berkeley, for a number of years. Late instar nymphs and apterous adults of the green peach aphid, Myzus persicae (Sulz.) reared on leafroll infected Physalis floridana plants or maintained for at least 15 days on such plants, except where otherwise mentioned, in order to ensure uniformly high inoculativity (serial transmissions showed that 100 per cent or nearly 100 per cent of such aphids were inoculative) were used for the transmission of the virus. The noninoculative stock colonies of $M$. persicae and Rhopalosiphum pseudobrassicae (Davis) were maintained on Indian mustard, Brassica juncea Coss., which is immune to leafroll virus (MacCarthy, 1954). Colonies of $M$. circumflexus (Buckton) and $M$. ornatus Laing were maintained on celery, and of Macrosteles fascifrons Stål, on barley.

The cages used to confine leafhoppers have been adequately described and illustrated (Severin, 1931). The split cage (fig. 1) used to confine aphid colonies on large plants was a modification of these and was $40 \mathrm{~cm}$ tall with a diameter of $25 \mathrm{~cm}$. A semicircular piece of denim with a small (5 cm dia.) circle cut in the center, large enough to accommodate the plant stem, was fixed on each half of the bottom plate to prevent any possible escape of wandering aphids.

In most experiments aphids were given access to the test plant by covering the test plant and the aphids with a cage. Three types of cages were used: (1) plastic cylinders with nylon net fixed on one end with acetone: (a) 23 $\mathrm{mm}$ long and $16 \mathrm{~mm}$ in diameter (fig. 2, no. 5), and (b) $42 \mathrm{~mm}$ long with $28 \mathrm{~mm}$ diameter (fig. 2, no. 4), (2) $90 \times 32 \mathrm{~mm}$ glass tubes as such (fig. 2 , no. 2 ) or with the bottom removed and replaced with a cotton cloth glued on the glass (fig. 2, no. 3), and (3) ethyl-cellulose cylinders approximately $17 \mathrm{~cm}$ tall and $6.8 \mathrm{~cm}$ in diameter covered with cloth at the top and with a clothcovered $3 \times 4 \mathrm{~cm}$ window for cross ventilation in order to reduce wetting of the inside of the cage by condensation of moisture (fig. 2, no. 1). The kind of cage used for any experiment depended upon plant size and suitability of the cage for that experiment.

To confine aphids to individual leaves, leaf-cages, gelatin capsules, and 'gelatin-capsule leaf-cages' were used. The standard leaf-cages consisted of 


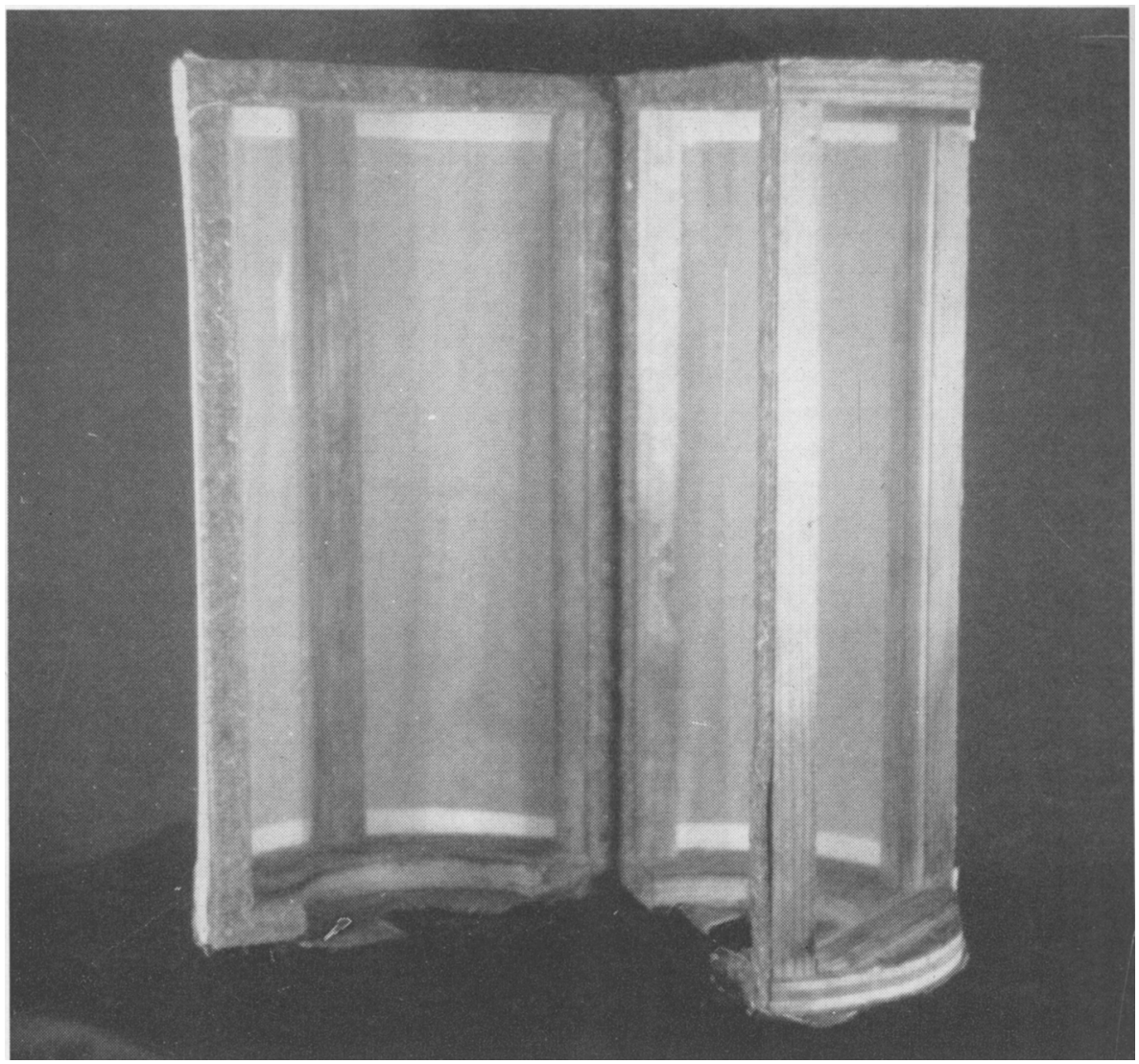

Fig. 1. Showing the split cage described on page 283 .

plastic cylinders $16 \mathrm{~mm}$ in diameter and $23 \mathrm{~mm}$ in length, one end of which was covered with nylon net and the other stoppered with a cork. The net end of the cage was placed on the leaf surface and a $2 \mathrm{~mm}$ thick $25 \times 15 \mathrm{~mm}$ wooden piece, with a $7 \mathrm{~mm}$ thick piece of foam rubber fixed on one side, was applied to the opposite surface of the leaf, foam rubber next to the leaf, and the two held in position with a rubber band (fig. 3).

In some experiments aphids were placed in the body of gelatin capsules and the open end was fixed on the leaf surface by applying a little pressure after moistening the edges (fig. 4) of the capsule. The gelatin capsules thus applied to the leaf would stay in position for up to five hours, after which period many of them would become dislodged. For confining aphids to small leaf areas for prolonged periods, 'gelatin-capsule leaf-cages' were used (fig. 5 ). These were made by attaching, at one end with adhesive tape, two $30 \times 10$ $\mathrm{mm}$ pieces of balsawood, one above the other, the upper $2.5 \mathrm{~mm}$ thick and the lower $1.5 \mathrm{~mm}$ thick. A hole of suitable size was bored with a cork borer through the center of the upper piece; the top of the gelatin capsule cap was ground off and the ground end fixed into this hole. The two pieces of balsa 


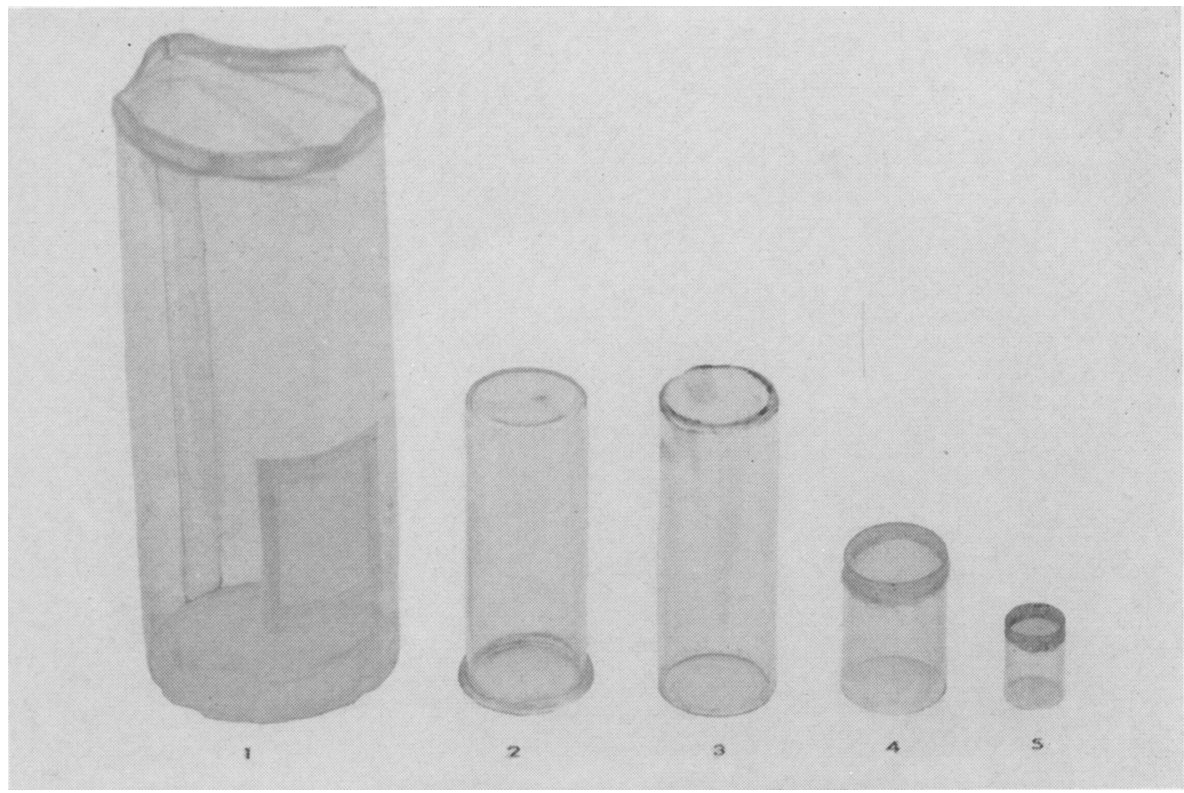

Fig. 2. Different cages used to confine the aphids to the whole plant: 1 . ethyl-cellulose cage, 2. glass tube, 3 . glass tube with the bottom replaced by cotton cloth, 4 . large plastic cage, and 5. small plastic cage.

wood were held apart, the leaf slid between them, the pieces closed just enough to touch the leaf surface, and fixed to the leaf by passing a pin through the unattached ends. Aphids then could be placed on the leaf within the cap with a camel's-hair brush, and enclosed there by gently sliding the body of the gelatin capsule into the cap. The body of the capsule could be easily lifted to remove or add aphids while the cage was fixed onto the leaf. Small holes were made in the cap and the body of the gelatin capsule. These allowed circulation of air and reduced the chances of the two gelatin parts sticking together because of moisture.

Aphids were collected with an aspirator either directly from the plants and from the interior of the cage, or after shaking the aphids onto a black silk cloth. After collection the insects were transferred to test plants or the cages with a camel's-hair brush.

As reported in the literature (MacCarthy, 1954), preliminary tests showed that Physalis angulata L. was not as suitable a test plant as was Physalis floridana, and so P. floridana was used throughout this work. Large numbers of seedlings in the cotyledon stage were transplanted in sterilized soil in 77 $\mathrm{mm}$ diameter sterilized pots. Sometimes large numbers of seeds were planted directly in $77 \mathrm{~mm}$ pots with two to three seeds in each pot. The plants used for any given experiments were chosen from the stock on the basis of uniformity of size and thriftiness. Unless otherwise indicated, plants were inoculated while still in the cotyledon stage or with the first true leaf still small, but no sooner than three days after transplanting to give the plants a chance to establish themselves. 


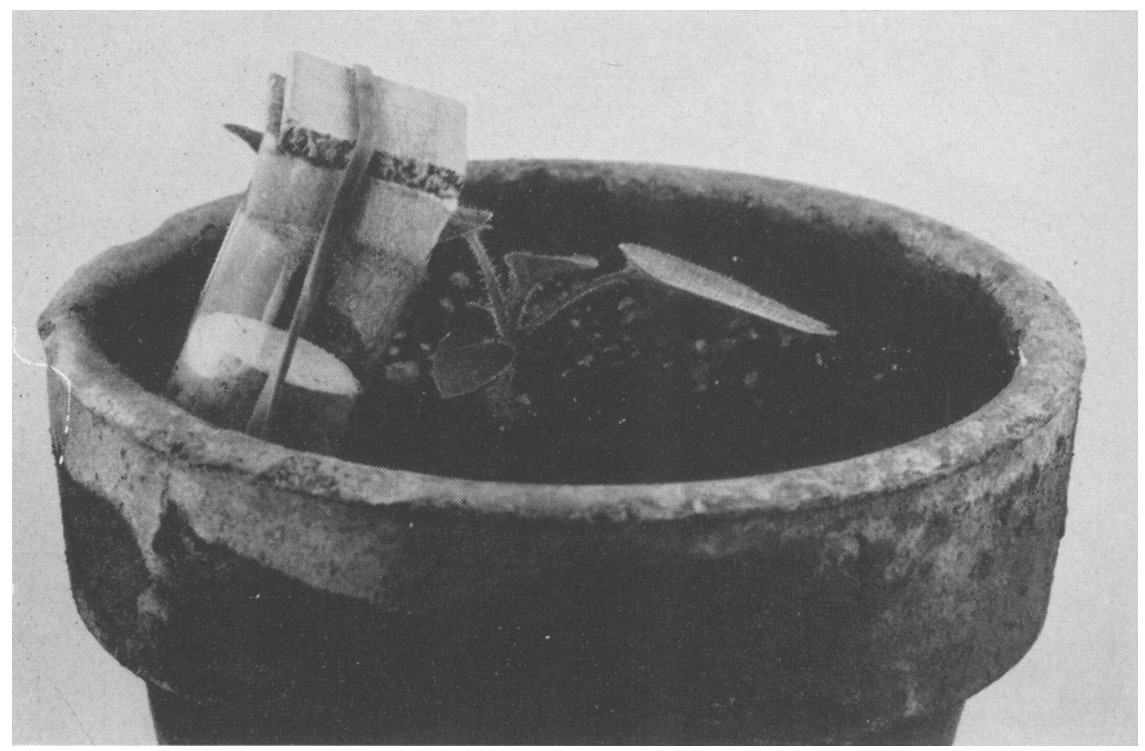

Fig. 3. The plastic leaf-cage used to confine aphids to a leaf of a 3-leaf stage Physalis floridana.

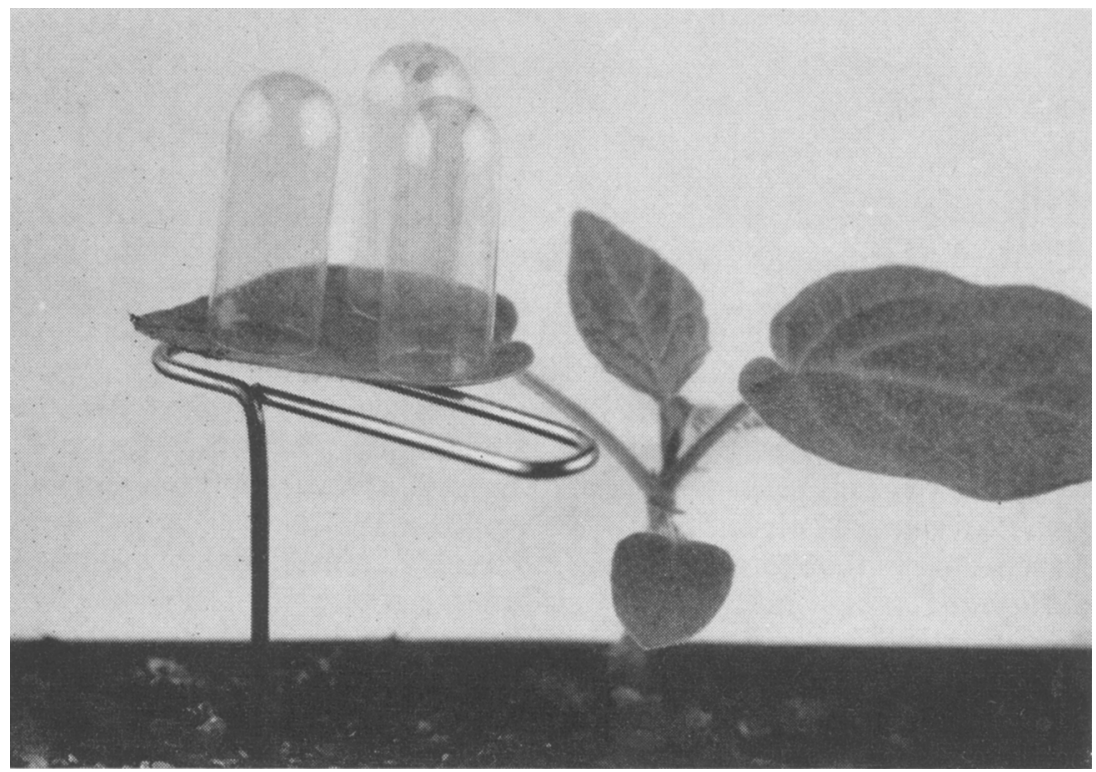

Fig. 4. The body of gelatin capsule size no. 3 in use to confine aphids to small leaf areas for short periods. In this figure each capsule contains one aphid, and was secured to the leaf by moistening the edge and pressing on the leaf surface. 


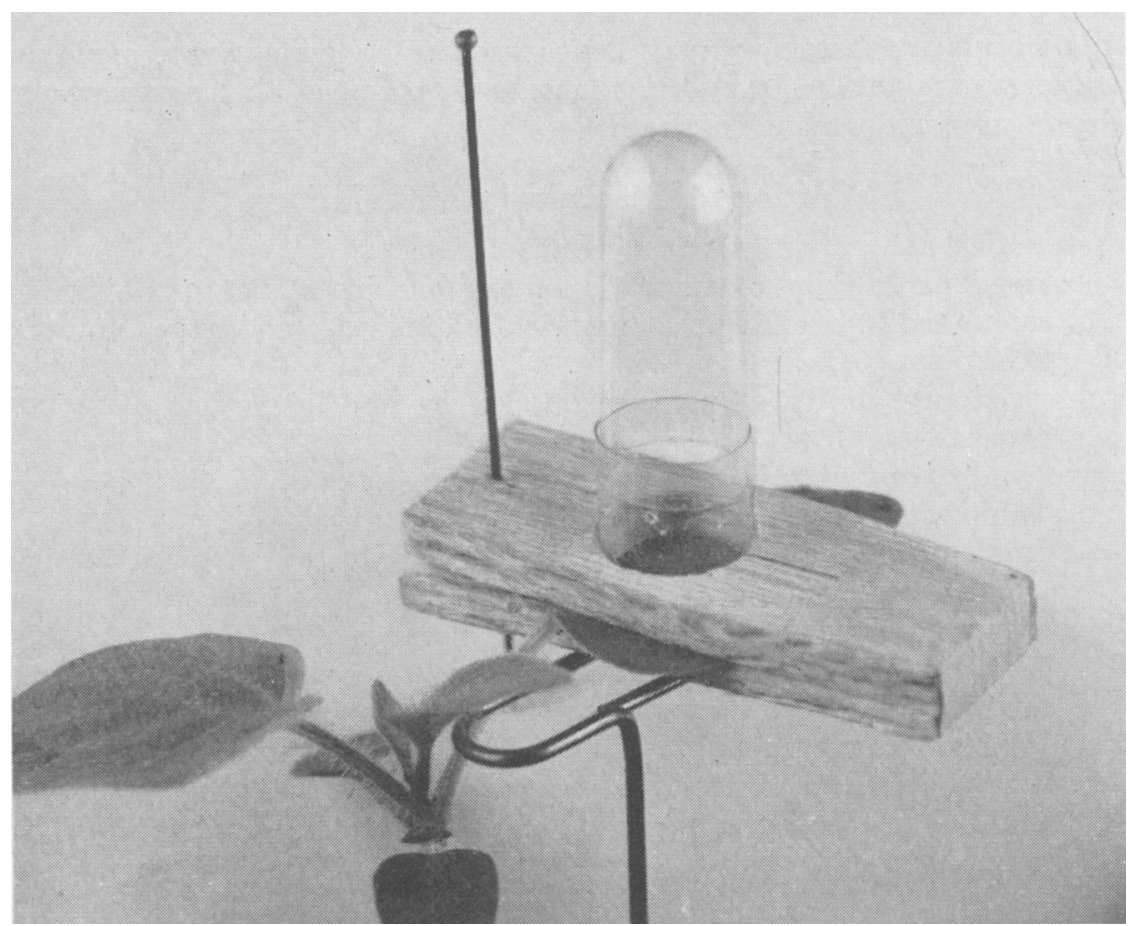

Fig. 5. The gelatin-capsule leaf-cage as used to confine aphids to a small leaf area for long periods. The leaf bearing the cage is held in position by a support improvised from a paper clip.

The inoculations were carried out in a headhouse. In experiments involving a long pretreatment of plants or a long inoculation feeding, the pots were set in a large tray on water-soaked vermiculite to meet the moisture requirements, and illumination was provided by fluorescent lamps. In the beginning these trays were placed in a headhouse but were later moved to a soil house in which temperatures were lower. In any given set of tests the conditions were comparable.

The plants required for an experiment were placed in rows. Each row contained one plant for each treatment. Taking one row at a time the plant for a particular treatment was selected and labeled at random. Inoculative aphids were placed on the plants of one row starting from one end and proceeding to the other before taking up the second row. This ensured randomization of test plants and the vector aphids. During the incubation period also the plants of different treatments were kept properly randomized.

After inoculation the plants were fumigated with nicotine and placed in a glasshouse for incubation. The plants were kept free of any aphid infestation by regular spraying with nicotine and/or malathion. Besides, the stock 
of test plants, inoculated plants, colonies of inoculative aphids, and colonies of noninoculative insects were all kept in separate glasshouses to avoid any possible contamination. In addition, checks were run in all the experiments to detect any accidental virus spread.

\section{Definitions of Statistical Abbreviations}

The statistical abbreviations used were as follows:

$p=$ observed probability of transmission for one insect per plant. This is calculated by dividing the number of plants infected by the number of total plants tested.

$q=$ observed probability of nontransmission by one insect per plant, and equals $1-p$.

$\mathrm{P}=$ probability of transmission by groups of $\mathrm{n}$ insects ( when $\mathrm{n}=1, \mathrm{P}=p$ ).

$\mathrm{Q}=$ probability of nontransmission by $\mathrm{n}$ insects per plant.

$\mathrm{p}^{*}=$ estimate of probability of transmission by one insect per plant obtained from multiple aphids. $\mathrm{p}^{*}=1-{ }^{\mathrm{n}} \mathrm{V} \mathrm{Q}$.

$\mathrm{p}^{*}{ }_{\text {av. }}=$ average of $\mathrm{p}^{*}$ estimated from observed values of $\mathrm{P}\left(\mathrm{P}_{\text {obs. }}\right)$ for $1,2,3$, $4, \ldots, n-1, n$ insects per plant. The maximum value of $\mathrm{p}^{*}$ that can be used for obtaining the average must be less than unity.

$\mathrm{P}^{*}{ }_{\mathrm{w} . \text { av. }}=$ weighted average of $\mathrm{p}^{*}$ obtained by multiplying each value of $\mathrm{p}^{*}$ with the number of insects used for inoculation before taking the average. Again the maximum value of $\mathrm{p}^{*}$ that can be used must be less than unity.

$\chi^{2}=$ chi square

d.f. $=$ degrees of freedom

$\mathrm{p}=$ probability

$>=$ greater than

$<=$ less than

\section{EXPERIMENTAL RESULTS \\ Serial Transmission of Potato Leafroll Virus by Myzus persicae (Sulz.)}

To test the percentage of inoculative aphids in the population of Myzus persicae used, three trials were carried out studying the serial transmission of potato leafroll virus to cotyledon stage Physalis floridana. In the first trial 25 aphids ( $M$. persicae) given a 12 days' acquisition access to $P$. floridana infected with the leafroll virus were transferred to new plants every 24 hours for three days. Transmissions were 80,65 , and 69 per cent on the first, second, and third transfer, respectively (table 1). In the second trial, 50 aphids reared on $P$. floridana virus source plant were tested likewise for four days. Table 2 shows that 72, 91.9, 80, and 60 per cent aphids transmitted on the first, second, third, and fourth transfer, respectively. Transmission on the first transfer was lower than on the second transfer perhaps because the plants used for the first transfer had been subjected to feeding by aphids for 15 days prior to inoculation: a depressing effect of aphid feeding prior to inoculation also was indicated in some other experiments. In the third trial, $41 M$. persicae tested were also reared on the virus source plant. Each aphid 
TABLE 1

SERIAL TRANSMISSION* OF POTATO LEAFROLL VIRUS TO PHYSALIS FLORIDANA BY MYZUS PERSICAE MAINTAINED ON INFECTED P. FLORIDANA FOR 12 DAYS, USING SINGLE APHID PER PLANT TRANSFERRED TO NEW PLANTS EVERY 24 HOURS

\begin{tabular}{|c|c|c|c|c|c|c|c|}
\hline \multirow{2}{*}{ Aphid number } & \multicolumn{3}{|c|}{ Transfer number } & \multirow{2}{*}{ Aphid number } & \multicolumn{3}{|c|}{ Transfer number } \\
\hline & 1 & 2 & 3 & & 1 & 2 & 3 \\
\hline $1 \ldots$ & + & $\mathrm{D} \dagger$ & .. & $14 \ldots \ldots \ldots \ldots$ & - & $\mathrm{D}$ & .. \\
\hline $2 \ldots$ & + & $\mathrm{D}$ & .. & $15 \ldots$ & + & $\mathrm{D}$ & \\
\hline $3 \ldots$ & - & - & + & 16. & - & + & + \\
\hline $4 \ldots$ & + & - & o & $17 \ldots$ & + & D & .. \\
\hline $5 \ldots$ & + & + & + & $18 \ldots$ & + & + & + \\
\hline $6 \ldots \ldots \ldots$ & + & - & D & $19 \ldots$ & + & - & + \\
\hline & - & + & + & 20. & + & + & - \\
\hline $8, \ldots \ldots \ldots \ldots \ldots$ & + & + & + & $21 .$. & + & $\mathrm{D}$ & \\
\hline $9 \ldots \ldots$ & + & + & - & 22. & + & + & + \\
\hline $10 \ldots \ldots \ldots \ldots \ldots \ldots$ & + & + & - & 23. & + & - & D \\
\hline $11 \ldots .$. & - & $\mathrm{D}$ & .. & 24. & + & + & $\mathrm{D}$ \\
\hline $12 \ldots$ & + & - & $\ddot{-}$ & 25. & + & $\mathrm{D}$ & \\
\hline \multirow[t]{2}{*}{$13 .}$. & + & + & + & Total $\neq \ldots \ldots \ldots \ldots$ & $20 / 25$ & $11 / 17$ & $9 / 13$ \\
\hline & & & & $\% \ldots \ldots \ldots \ldots \ldots$ & 80.0 & 64.7 & 69.2 \\
\hline
\end{tabular}

$*+,-$, and $O$ mean plants infected, uninfected, and dead, respectively.

$\dagger \mathrm{D}$ means aphid died during preceding 24 hours.

$\ddagger$ Numerator represents plants infected and the denominator total plants tested.

was given inoculation access for two and four days on the first and second plants, respectively; and about 95 per cent aphids transmitted during each period (table 3).

An examination of tables 1 to 3 shows that 106 out of 116 aphids tested in the three trials transmitted the virus to at least one plant, the remaining 10 died before the second transfer. This showed that 100 per cent or nearly so of the aphids maintained on Physalis floridana plant infected with the leafroll virus for 12 days or reared on it were inoculative. High percentage of transmission even on the second, third, and fourth 24 hourly transfers showed that the virus was persistent in its aphid vector. This mode of transmission is well known for the potato leafroll virus, and the results only confirm the identity of the virus being studied established earlier on the basis of symptoms.

\section{Duration of Inoculation Access Period in Relation to Transmission of Potato Leafroll Virus by Groups of 10 Aphids Per Plant}

The Kirkpatrick-Ross hypothesis suggests that aphid feeding during a long inoculation access would tend to increase plant resistance to systemic infection with potato leafroll virus and that this, in part, is the cause of the actual transmission by groups of aphids to be lower than that expected under binomial assumptions (Kirkpatrick and Ross, 1952; Williams and Ross, 1957). If feeding by groups of inoculative aphids on the test plants induced the plants to be more resistant to infection, this effect might increase as the duration of inoculation access is increased, and consequently less transmission might occur as the inoculation access period is prolonged. 
TABLE 2

SERIAL TRANSMISSION* OF POTATO LEAFROLL VIRUS TO PHYSALIS FLORIDANA BY MYZUS PERSICAE REARED ON THE SOURCE PLANT, SINGLE APHID PER PLANT TRANSFERRED TO NEW PLANT EVERY 24 HOURS

\begin{tabular}{|c|c|c|c|c|c|c|c|c|c|}
\hline \multirow{2}{*}{$\begin{array}{c}\text { Aphid } \\
\text { number }\end{array}$} & \multicolumn{4}{|c|}{ Transfer number } & \multirow{2}{*}{$\begin{array}{c}\text { Aphid } \\
\text { number }\end{array}$} & \multicolumn{4}{|c|}{ Transfer number } \\
\hline & $1 \dagger$ & $2 \ddagger$ & 3 & 4 & & $1 \dagger$ & $2 \ddagger$ & 3 & 4 \\
\hline $1 \ldots$ & + & + & + & + & $27 \ldots$ & + & + & + & D \\
\hline $2 .$. & + & - & $D \S$ & .. & 28. & + & + & + & - \\
\hline 3.. & + & - & - & - & 29. & + & + & + & - \\
\hline $4 \ldots$ & + & + & + & + & 30. & + & + & D & .. \\
\hline 5. & - & + & + & D & $31 .$. & - & + & + & - \\
\hline 6. & - & $\mathrm{D}$ & .. & .. & $32 .$. & + & $\mathrm{D}$ & & .. \\
\hline 7. & - & $\mathrm{D}$ & .. & .. & $33 .$. & - & + & + & + \\
\hline 8. & + & + & + & + & $34 .$. & - & + & $\mathrm{D}$ & \\
\hline 9. & + & + & + & + & 35. & + & + & + & $\mathrm{D}$ \\
\hline 10 . & + & + & + & D & 36. & - & D & .. & .. \\
\hline $11 .$. & + & + & + & + & $37 .$. & - & $\mathrm{D}$ & .. & .. \\
\hline $12 \ldots$ & - & $\mathrm{D}$ & & & 38. & + & D & .. & .. \\
\hline $13 \ldots \ldots$ & + & + & + & + & $39 .$. & - & $\mathrm{D}$ & & .. \\
\hline $14 \ldots$ & + & + & + & $\mathrm{D}$ & 40. & + & + & + & + \\
\hline $15 \ldots$ & + & + & - & - & $41 .$. & - & + & - & - \\
\hline $16 \ldots$ & + & + & + & + & $42 .$. & + & + & + & $\mathrm{D}$ \\
\hline $17 \ldots$ & + & + & + & + & $43 .$. & + & + & + & D \\
\hline 18. & + & $\mathrm{D}$ & & .. & $44 .$. & + & D & & .. \\
\hline $19 \ldots$ & - & + & D & .. & $45 .$. & - & - & D & .. \\
\hline 20. & + & + & + & D & $46 .$. & + & D & .. & .. \\
\hline 21 . & + & + & - & - & 47. & + & D & .. & .. \\
\hline $22 .$. & + & + & + & + & $48 .$. & + & D & & .. \\
\hline 23. . & + & + & $\mathrm{D}$ & .. & $49 .$. & + & + & D & \\
\hline $24 .$. & + & + & + & - & 50. & - & + & - & D \\
\hline $25 \ldots$ & + & + & + & + & Totall. & $36 / 50$ & $34 / 37$ & $24 / 30$ & $12 / 20$ \\
\hline 26. & + & + & - & D & $\% \ldots$ & 72.0 & 91.9 & 80.0 & 60.0 \\
\hline
\end{tabular}

$*+$, and - mean plants infected and uninfected, respectively.

$\dagger 15$ or more noninoculative Myzus persicae were allowed access to each test plant for two weeks before inoculation; dead aphids were not removed; kept shaded but artificially illuminated 24 hours every day.

$\ddagger$ Plants treated same way as above but no noninoculative aphids allowed on them.

$\$ \mathrm{D}$ means that the aphid died during the previous 24 hours.

$\|$ Numerator represents plants infected and the denominator total plants tested.

In order to test the effect of duration of inoculation access, 10 inoculative Myzus persicae per plant were given one half, one, two, and four hours, and seven days of inoculation access. A total of 50 plants per treatment was inoculated in a two-trial series. Table 4 shows that transmission was 88 per cent approximately, with one half and one hour of inoculation access. It reached 100 per cent level with two hours of access and stayed at that maximum level for longer periods of inoculation access. Another experiment compared inoculation by groups of $10 M$. persicae over four hours with seven days; three trials of another experiment compared transmission over one and seven days, and a final experiment was done to determine transmission over seven days of inoculation access period more extensively. All of the 378 plants that were exposed to inoculation for two hours or longer (up to seven days) became infected. Thus, there was no decrease in transmission as the inoculation access, which would be roughly the same as the period of aphid feeding, was increased. This was taken to indicate that feeding by groups of inoculative aphids during a long inoculation access to Physalis floridana did 
TABLE 3

SERIAL TRANSMISSION* OF POTATO LEAFROLL VIRUS TO PHYSALIS FLORIDANA BY MYZUS PERSICAE REARED ON THE VIRUS SOURCE PLANT

\begin{tabular}{|c|c|c|c|c|c|c|c|c|}
\hline \multirow{2}{*}{$\begin{array}{c}\text { Aphid } \\
\text { number }\end{array}$} & \multicolumn{2}{|c|}{ Transfer number } & \multirow{2}{*}{$\begin{array}{c}\text { Aphid } \\
\text { number }\end{array}$} & \multicolumn{2}{|c|}{ Transfer number } & \multirow{2}{*}{$\begin{array}{c}\text { Aphid } \\
\text { number }\end{array}$} & \multicolumn{2}{|c|}{ Transfer number } \\
\hline & $1 \dagger$ & $2 \ddagger$ & & $1 \dagger$ & $2 \ddagger$ & & $1 \dagger$ & $2 \ddagger$ \\
\hline 1.. & + & + & 16. & + & + & & + & + \\
\hline $2 .$. & + & + & 17. & + & + & $32 .$. & + & + \\
\hline 3. & + & $\mathrm{D} \S$ & 18. & + & + & 33. & + & + \\
\hline 4. & + & + & 19. & + & + & $34 \ldots$ & + & + \\
\hline 5. & + & + & 20. & + & + & $35 .$. & + & + \\
\hline $6 \ldots$ & + & + & $21 \ldots$ & + & + & 36. & + & + \\
\hline $7 \ldots$ & + & + & $22 .$. & + & + & $37 .$. & + & + \\
\hline $8 \ldots$ & - & + & 23. & + & + & 38. & + & + \\
\hline 9. & + & + & $24 .$. & + & - & $39 .$. & + & + \\
\hline 10. & + & + & 25. & + & + & $40 .$. & + & + \\
\hline 11.. & + & + & 26. & - & o & $41 \ldots$ & + & + \\
\hline 12. & + & - & 27. & + & + & Total... & $39 / 41 \|$ & $37 / 39$ \\
\hline $13 \ldots$ & + & + & 28. & + & + & & 95.1 & 94.9 \\
\hline $14 \ldots \ldots \ldots \ldots$ & + & + & $29 .$. & + & + & & & \\
\hline $15 \ldots \ldots$ & + & + & 30. & + & + & & & \\
\hline
\end{tabular}

$*+,-$, and $\mathrm{O}$ represent infected, uninfected, and dead plants, respectively.

t Single aphid allowed on the first plant for two days.

t Single aphid allowed on the second plant for four days.

Aphid died before second transfer.

Numerator represents plants infected and denominator the total plants tested.

TABLE 4

TRANSMISSION OF POTATO LEAFROLL VIRUS TO PIIYSALIS FLORIDANA BY GROUPS OF 10 MYZUS PERSICAE DURING VARIOUS LENGTHS OF INOCULATION ACCESS

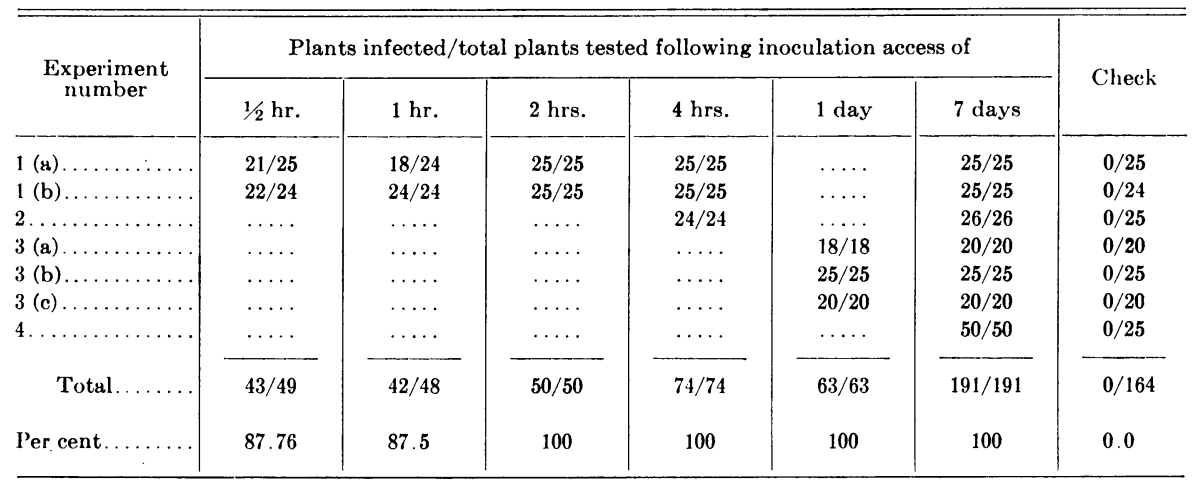

not decrease its susceptibility to systemic infection with potato leafroll virus, or if it did it could not overcome the effect of introduction of inoculum early in the inoculation access period. Thus, the experiments failed to provide evidence for the hypothesis that aphid feeding itself, during a long inoculation access period, would result in the actual transmission of potato leafroll virus by groups of aphids to be lower than the expected value calculated according to the binomial theorem. 
TABLE 5

RESULTS OF TEST TO DETERMINE THE PRESENCE OF PLANTS IMMUNE OR HIGHLY RESISTANT TO THE POTATO LEAFROLL VIRUS IN THE PHYSALIS FLORIDANA TEST PLANT POPULATION

\begin{tabular}{|c|c|c|}
\hline \multirow{2}{*}{ Age of plants } & \multicolumn{2}{|c|}{ Plants infected/total plants tested } \\
\hline & Inoculated ${ }^{*}$ & Check \\
\hline 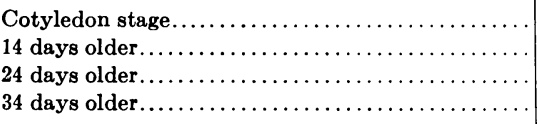 & $\begin{array}{c}241 / 241 \\
136 / 136 \\
74 / 75 \dagger \\
12 / 12\end{array}$ & $\begin{array}{l}0 / 238 \\
0 / 123 \\
0 / 12 \\
0 / 12\end{array}$ \\
\hline 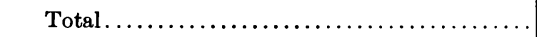 & $463 / 464$ & $0 / 385$ \\
\hline
\end{tabular}

* Each plant inoculated by giving 48 hours' inoculation access to 5 inoculative Myzus persicae reared on infected Physalis foridana.

$\dagger$ The single noninfected plant became infected 10 days after reinoculation.

TABLE 6

RESULTS OF TRIALS TO DETERMINE THE EFFECT OF WITHHOLDING WATER FROM THE TEST PLANTS BEFORE INOCULATION ON THE TRANSMISSION OF POTATO LEAFROLL VIRUS TO PHYSALIS FLORIDANA BY SINGLE MYZUS

PERSICAE GIVEN 48 HOURS OF FEEDING ACCESS ON TEST PLANTS

\begin{tabular}{c|c|c|c|c}
\hline \hline \multirow{2}{*}{$\begin{array}{c}\text { Experiment } \\
\text { number }\end{array}$} & $\begin{array}{c}\text { Duration of } \\
\text { withholding } \\
\text { water }\end{array}$ & \multicolumn{2}{|c}{ Plants infected/total plants tested } \\
\cline { 3 - 5 } & Water withheld & Watered & Absolute check \\
\hline $1 \ldots \ldots \ldots \ldots \ldots \ldots$ & 4 days & $21 / 29$ & $21 / 29$ & $0 / 25$ \\
$2 \ldots \ldots \ldots \ldots \ldots$ & 5 days & $26 / 29$ & $25 / 30$ & $0 / 26$ \\
\hline
\end{tabular}

\section{Test of the Resistance of Physalis floridana Rydb. to Systemic Infection with Potato Leafroll Virus}

In tests reported so far not all plants were infected following an inoculation access period. It was considered desirable to subject a large number of test plants to aphid inoculation to get a better estimate of the percentage of the test plant population which could escape systemic infection with leafroll virus following exposure to inoculative aphids. Whether the plants which failed to be infected after a suitable inoculation access by aphids were actually highly resistant or immune could then be determined by exposing these plants a second or third time to inoculative aphids.

A set of 241 plants in the cotyledon stage, 136 plants 14 days older, 74 plants 24 days older, and 12 plants 34 days older was tested by confining 5 aphids for an inoculation access period of 48 hours on each plant using glass tubes for the younger of the two groups of plants and ethyl-cellulose cages for the others. Checks were also run. The results (table 5) show that 463 out 
of a total of 464 plants were infected. The fact that only one out of 464 plants used in this experiment failed to become infected following a 48 hours' inoculation access to 5 aphids per plant and that this plant became infected following reinoculation was interpreted to mean that the Physalis floridana test plant population used in this work was relatively free of immune plants and there were very few 'resistant' plants. It was, therefore, considered that the hypothesis of presence of immune or highly resistant plants in the $P$. floridana test plant population would not explain a failure of values of actual transmission, of the potato leafroll virus by 5 Myzus persicae per plant during a 48 hours' inoculation access, to equal the calculated expected values of transmission based upon the binomial theorem.

\section{Attempts to Find if Partial Wilting of Physalis floridana Affects the Transmission of Aphid-Borne Potato Leafroll Virus to This Plant}

Physalis floridana plants in cotyledon stage were kept in shade and artificially illuminated. Water was withheld for four days from one half of these (treated) plants, and the other half (checks) were regularly watered. These plants were then tested by allowing single inoculative Myzus persicae 48 hours' access to each plant. Absolute checks consisting of noninoculated plants were also run. In another experiment the effect of withholding water for five days was tested.

In both the experiments (table 6), there was no evidence of any effect of partial wilting, induced by withholding water for four or five days, on the systemic infection of Physalis floridana with the potato leafroll virus. Thus, the reported depression in the transmission of potato leafroll virus due to prolonged aphid feeding prior to inoculation, could not be simulated by a simple decrease in turgidity.

\section{Tests of the Possible Interference in Feeding Due to Grouping the Vectors and Its Influence upon Transmission of the Potato Leafroll Virus}

To study the interference of inoculative aphids with one another in feeding on the test plants during inoculation access times and its effect upon transmission of the potato leafroll virus, an experiment consisting of the following six treatments was done: (1) 1 aphid was confined on a leaf; (2) 2 aphids, each of which was confined separately on the same leaf; (3) 2 aphids, both of which were confined under the same cage on a leaf; (4) 3 aphids, each confined separately on the same leaf; (5) 3 aphids, all confined together under the same cage on a leaf; and (6) untreated check. The cage used to confine the aphids consisted of the body of a gelatin capsule (size no. 3 ) which was $5.5 \mathrm{~mm}$ in diameter and $13 \mathrm{~mm}$ high (fig. 4).

The required number of aphids were placed in the gelatin eapsule with a camel's-hair brush. The open end of the capsule was moistened (licking the edge quickly was satisfactory) and quickly applied to the upper surface of the leaf using a little pressure. The cages were left in place for five hours. During the inoculation access period observations were made at regular in- 
tervals to note the number of aphids sitting on the leaf surface in feeding position, that is, with the head pressed down. The plants were incubated and the resulting transmissions recorded. $\Lambda$ series of four trials was conducted using a total of 209 plants in four-leaf stage, and 382 inoculative aphids.

Average numbers of aphids feeding in different treatments during the inoculation access time were obtained by dividing the sum of the number of aphids seen in feeding position at various intervals for all the plants of a treatment by the product of number of plants and the number of times observations were made. The figures obtained for each experiment and the over-all averages of the four trials comprising the series are presented in table 7. The results indicated that there was little interference in feeding. The average number of aphids feeding in groups of 2 and 3 aphids per plant

TABLE 7

INFLUENCE OF SEPARATING OR GROUPING OF INOCULATIVE MYZUS

PERSICAE UPON FEEDING ON PHYSALIS FLORIDANA DURING AN INOCULATION ACCESS PERIOD OF FIVE HOURS

\begin{tabular}{|c|c|c|c|c|c|c|c|}
\hline \multirow{3}{*}{$\begin{array}{c}\text { Trial number of } \\
\text { table } 5\end{array}$} & \multirow{3}{*}{$\begin{array}{c}\text { Number } \\
\text { of } \\
\text { plants } \\
\text { per } \\
\text { treat- } \\
\text { ment }\end{array}$} & \multirow{3}{*}{$\begin{array}{c}\text { Number } \\
\text { of } \\
\text { obser- } \\
\text { vations }\end{array}$} & \multicolumn{5}{|c|}{ Average numbers of aphids feeding in different treatments } \\
\hline & & & \multirow{2}{*}{$\begin{array}{l}1 \text { aphid } \\
\text { per plant }\end{array}$} & \multicolumn{2}{|c|}{2 aphids per plant } & \multicolumn{2}{|c|}{3 aphids per plant } \\
\hline & & & & Singly & Grouped & Singly & Grouped \\
\hline 1. & 9 & 4 & 0.750 & 1.333 & 1.333 & 2.100 & 2.406 \\
\hline 2. & 7 & 7 & 0.878 & 1.388 & 1.471 & 2.327 & 2.061 \\
\hline 3. & 10 & 8 & 0.813 & 1.587 & 1.713 & 2.512 & 2.475 \\
\hline 4. & 10 & 10 & 0.470 & 1.060 & 1.060 & 1.490 & 1.190 \\
\hline Average. & .. & .. & 0.7275 & 1.334 & 1.454 & 2.107 & 2.033 \\
\hline
\end{tabular}

whether caged singly or in groups were roughly in arithmetical proportion with the value for single aphids. Thus, the average values of aphids feeding were 0.7275 for single aphids, 1.334 and 1.454 for two aphids singly and in groups, 2.107 and 2.033 for three aphids singly and in groups, respectively.

The transmission results (table 8) show that groups of 2 and 3 aphids when confined together produced more infections than when the same number of aphids per plant were confined singly: the actual values were 82.85 and 96.97 as against 74.28 and 91.66 per cent, respectively. The actual superior performance of the groups versus the same number confined singly should not be construed as supporting a mass-action hypothesis since the evidence for superiority has no statistical support. The results indicated that in general multiple aphids failed to achieve the transmission expectation under the binomial assumptions (assuming that the actual value obtained by the single insects was the expected), but again chi square analysis of the deviations placed such discrepancies well within the range of chance variation.

In any event, the results failed to support the hypothesis that interference is one of the factors responsible for the actual transmission of the potato leafroll virus by groups of aphids to be lower than values of transmission expected according to the binomial theorem. 
TABLE 8

TRANSMISSION OF POTATO LEAFROLL VIRUS TO PHYSALIS FLORIDANA BY SINGLE MYZUS PERSICAE AND GROUPS CONFINED SINGLY OR GROUPED TOGETHER DURING AN INOCULATION ACCESS PERIOD OF FIVE HOURS

\begin{tabular}{|c|c|c|c|c|c|c|}
\hline \multirow{3}{*}{ Trial number } & \multicolumn{6}{|c|}{ Number of aphids used per plant } \\
\hline & \multirow{2}{*}{0} & \multirow{2}{*}{1} & \multicolumn{2}{|c|}{2} & \multicolumn{2}{|c|}{3} \\
\hline & & & Singly & Grouped & Singly & Grouped \\
\hline 1. & $0 / 9^{*}$ & $6 / 9$ & $6 / 9$ & $7 / 9$ & $8 / 10$ & $8 / 8$ \\
\hline $2 \ldots$ & $0 / 7$ & $6 / 7$ & $6 / 7$ & $6 / 7$ & $6 / 6$ & $7 / 7$ \\
\hline $3 \ldots$ & $0 / 10$ & $8 / 10$ & $8 / 10$ & $8 / 10$ & $10 / 10$ & $9 / 10$ \\
\hline $4 \ldots$. & $0 / 9$ & $3 / 9$ & $6 / 9$ & $8 / 9$ & $9 / 10$ & $8 / 8$ \\
\hline Total. & $0 / 35$ & $23 / 35$ & $26 / 35$ & $29 / 35$ & $33 / 36$ & $32 / 33$ \\
\hline Actual per cent. . & 0.0 & 65.7 & 74.28 & 82.85 & 91.66 & 96.97 \\
\hline Expected per cent... & 0.0 & 65.7 & 88.2 & 88.2 & 96.0 & 96.0 \\
\hline
\end{tabular}

* Numerator represents number of plants infected and denominator the total plants tested.

TABLE 9

INFLUENCE OF SEPARATING OR GROUPING INOCULATIVE APHIDS ON PHYSALIS FLORIDANA UPON FEEDING DURING AN INOCULATION ACCESS PERIOD OF $60 \pm 2$ MINUTES

\begin{tabular}{|c|c|c|c|c|c|c|}
\hline \multirow{3}{*}{$\begin{array}{l}\text { Trial number } \\
\text { of table } 10\end{array}$} & \multirow{3}{*}{$\begin{array}{l}\text { Number of } \\
\text { plants per } \\
\text { treatment }\end{array}$} & \multicolumn{5}{|c|}{$\begin{array}{c}\text { Average number of aphids feeding at the end of inoculation } \\
\text { access in different treatments }\end{array}$} \\
\hline & & \multirow{2}{*}{$\begin{array}{l}1 \text { aphid } \\
\text { per plant }\end{array}$} & \multicolumn{2}{|c|}{2 aphids per plant } & \multicolumn{2}{|c|}{3 aphids per plant } \\
\hline & & & Singly & Grouped & Singly & G rouped \\
\hline 1. & 10 & 0.6 & 0.9 & 1.0 & 1.3 & 1.2 \\
\hline 3. & 20 & 0.75 & 1.5 & 1.5 & 2.0 & 2.6 \\
\hline 4. & 18 & 0.66 & 1.17 & 1.06 & 1.8 & 1.7 \\
\hline $5 \ldots$ & 20 & 0.35 & 1.2 & 1.4 & 2.0 & 1.75 \\
\hline $6 \ldots \ldots \ldots \ldots$ & 20 & 0.6 & 1.4 & 1.65 & 2.15 & 2.05 \\
\hline $7 \ldots \ldots \ldots \ldots$ & 20 & 0.8 & 1.4 & 1.45 & 1.93 & 2.2 \\
\hline Average. & .. & 0.577 & 1.187 & 1.26 & 1.758 & 1.817 \\
\hline
\end{tabular}

A second experiment consisted of seven trials identical with those in the last series, but with an inoculation access period of $60 \pm 2$ minutes instead of five hours; a total of 707 plants in four-leaf stage and 1297 aphids was used. The shorter inoculation access was used in an attempt to better detect any interference among inoculative aphids in feeding upon the test plant. If any interference in feeding existed, the interference and its probable unfavorable effect on transmission might be much greater in case of an inoculation access of one hour than that of five hours because the shorter the inoculation access the less chance there would be for an inoculative aphid to feed for a time long enough for transmission. 
Observations on feeding of aphids were taken only at the end of the inoculation access period. Table 9 shows that the values of over-all average of aphids feeding at the end of inoculation access in case of groups of two and three aphids again was almost in arithmetical proportion with that for single aphids. Further, these values were slightly more in case of groups of 2 and 3 aphids caged together than when each was allowed inoculation access in a separate cage, the actual values being 1.26 and 1.817 as against 1.187 and 1.758 , respectively. Thus, during a short inoculation access of one hour, just as in the case of five hours' long inoculation access, individuals in groups of 2 and 3 aphids failed to give evidence of interference in feeding.

TABLE 10

TRANSMISSION OF POTATO LEAFROLL VIRUS TO PHYSALIS FLORIDANA

BY SINGLE MYZUS PERSICAE AND GROUPS CONFINED SINGLY OR GROUPED TOGETHER DURING AN INOCULATION ACCESS PERIOD OF $60 \pm 2$ MINUTES

\begin{tabular}{|c|c|c|c|c|c|c|}
\hline \multirow{3}{*}{ Trial number } & \multicolumn{6}{|c|}{ Number of aphids used per plant } \\
\hline & \multirow[b]{2}{*}{0} & \multirow[b]{2}{*}{1} & \multicolumn{2}{|c|}{2} & \multicolumn{2}{|c|}{3} \\
\hline & & & Singly & Grouped & Singly & Grouped \\
\hline 1. & $0 / 10^{*}$ & $1 / 10$ & $5 / 10$ & $2 / 10$ & $1 / 10$ & $2 / 10$ \\
\hline $2 \ldots$ & $0 / 10$ & $1 / 9$ & $5 / 10$ & $1 / 10$ & $3 / 10$ & $5 / 10$ \\
\hline $3 \nmid \ldots \ldots$ & $0 / 20$ & $5 / 20$ & $8 / 20$ & $5 / 20$ & $9 / 20$ & $11 / 20$ \\
\hline $4 \ddagger \ldots \ldots \ldots \ldots \ldots$ & $0 / 18$ & $1 / 18$ & $3 / 18$ & $3 / 18$ & $4 / 18$ & $1 / 18$ \\
\hline $5 \ldots$ & $0 / 20$ & $7 / 20$ & $6 / 20$ & $7 / 20$ & $10 / 20$ & $9 / 20$ \\
\hline $6 \ldots \ldots \ldots \ldots \ldots \ldots \ldots \ldots \ldots \ldots$ & $0 / 20$ & $2 / 20$ & $4 / 20$ & $10 / 20$ & $10 / 20$ & $7 / 20$ \\
\hline $7 \ldots \ldots \ldots \ldots \ldots \ldots \ldots \ldots \ldots$ & $0 / 20$ & $3 / 20$ & $4 / 20$ & $8 / 20$ & $10 / 20$ & $9 / 20$ \\
\hline Total... & $0 / 118$ & $20 / 117$ & $35 / 118$ & $36 / 118$ & $47 / 118$ & $44 / 118$ \\
\hline Actual per cent.............. & 0.0 & 17.09 & 29.66 & 30.51 & 39.83 & 37.29 \\
\hline Expected per cent.......... & 0.0 & 17.09 & 31.3 & 31.3 & 43.0 & 43.0 \\
\hline
\end{tabular}

* Numerator represents the number of plants infected and the denominator the total plants tested.

+ Virus acquisition access to infected Physalis floridana was six days in trial 3.

$\ddagger$ Virus acquisition access to infected Physalis floridana was nine days in trial 4.

The infections resulting from groups of two aphids confined together (table 10) were 0.8 per cent more than those caused by the same number of insects confined singly. In case of groups of 3 aphids the infections resulting from aphids confined together were fewer by 2.5 per cent than those from the same number of aphids confined singly. Again, the evidence for difference was not significant.

In these two experiments, individuals of groups of 2 and 3 aphids confined together were allowed less leaf area (11.4 and $7.9 \mathrm{sq} \mathrm{mm}$, respectively) than would fall as a share to each of a group of 10 aphids confined on a Physalis floridana plant in the cotyledon stage. Thus, the amount of competition for finding a place to feed under the present experimental conditions would be greater than under the conditions of some other experiments. Presumably, this increased competition for finding a place to feed, and reduction in the inoculation access period to five hours and then to one hour would have emphasized any interference in feeding by individuals of a group, and exag- 
gerated any reduction in transmission of the potato leafroll virus. However, as evidenced both by the numbers of aphids feeding during and at the end of inoculation access period, and by the number of resulting infections there was no measurable interference in feeding among individuals of groups of aphids. Thus, in the transmission of potato leafroll virus, experimental evidence failed to support the hypothesis that interference resulting from group feeding is one of the factors causing actual values of transmission by groups of insects not to obtain the levels expected under the binomial assumptions. There remains but the last explanatory hypothesis of Kirkpatrick and Ross (1952) to be tested, viz., vector feeding decreases the plant susceptibility.

TABLE 11

TRANSMISSION OF POTATO LEAFROLL VIRUS TO PHYSALIS FLORIDANA BY SINGLE AND GROUPS OF MYZUS PERSICAE GIVEN AN INOCULATION ACCESS FOR 48 HOURS

\begin{tabular}{|c|c|c|c|c|c|c|c|c|c|}
\hline \multirow{2}{*}{$\begin{array}{l}\text { Number of aphids } \\
\text { per plant }\end{array}$} & \multicolumn{6}{|c|}{$\begin{array}{l}\text { Plants infected/total plants } \\
\text { tested in trial number* }\end{array}$} & \multirow{2}{*}{ Total } & \multicolumn{2}{|c|}{$\begin{array}{l}\text { Percentage } \\
\text { transmission }\end{array}$} \\
\hline & 1 & 2 & 3 & 4 & 5 & 6 & & Actual & Expected \\
\hline 0. & $0 / 10$ & $0 / 8$ & $0 / 4$ & $0 / 3$ & $0 / 12$ & $0 / 12$ & $0 / 49$ & 0.00 & 0.00 \\
\hline 1. & $5 / 10$ & $5 / 8$ & $3 / 4$ & $0 / 4$ & $9 / 12$ & $7 / 12$ & $29 / 50$ & 58.00 & 58.00 \\
\hline $5 \ldots \ldots$ & $9 / 9$ & $8 / 8$ & $4 / 4$ & $2 / 4$ & $12 / 12$ & $9 / 12$ & $44 / 49$ & 89.796 & 98.69 \\
\hline $10 \ldots \ldots \ldots \ldots \ldots \ldots \ldots$ & $10 / 10$ & $8 / 8$ & $4 / 4$ & $4 / 4$ & $12 / 12$ & $12 / 12$ & $50 / 50$ & 100.00 & 99.98 \\
\hline
\end{tabular}

* Virus source plant for trials 1 to 3 was Netted Gem potato, and for trials 4 to 6 Physalis floridana; virus acquisition access period being five and eight days, respectively.

\section{Effect of Insect Feeding on 'Plant Susceptibility' to Virus Infection Effect of Number of Inoculative Myzus persicae on Transmission of Potato Leafroll Virus to Physalis floridana During Long Inoculation Access Periods}

A series of six trials using $0,1,5$, and 10 inoculative Myzus persicae per plant was conducted. An inoculation access period of approximately 48 hours was given on the test plant, Physalis floridana, by putting the aphids into glass tubes $(90 \times 32 \mathrm{~mm})$ and inverting the tube over the plant. The results obtained are presented in table 11 , as are the expected values of transmission by groups of 5 and 10 aphids, calculated on the basis of actual transmission by single aphids. Assuming that there is no mass-action, and that transmission by individuals in a colony is an independent and separate event, the expected values referred to above were obtained as follows: probability $(p)$ of transmission by single insects $=0.58$ ( 29 plants infected out of 50$)$; probability of nontransmission $(q)$ by single aphids $=1-p=1-0.58=0.42$; the probability of transmission by 5 aphids $\left(1-q^{5}\right)$ per plant $=1-0.42^{5}=0.9869$; and likewise probability of transmission by 10 aphids $\left(1-q^{10}\right)$ per plant $=1-0.42^{10}$ or 0.9998 .

The actual value of transmission by 5 aphids per plant was somewhat less than the calculated expected value, but with 10 aphids per plant no such trend was found. 


\section{Effect of Number of Inoculative Myzus persicae on Transmission of Potato Leafroll Virus to Physalis floridana During Short Inoculation Access Periods}

In the work reported above little experimental evidence has been gained in support of either the 'plant resistance' or 'feeding interference' considered by Kirkpatrick and Ross (1952) to explain the reduction in the transmission by groups of insects of aphid-borne potato leafroll virus below that expected under binomial assumptions. Further tests on the effect of vector numbers on transmission of this virus were done in order to see how much of the departure of actual values from expected ones might be attributable to chance variation under conditions in which the observed transmission by groups of

TABLE 12

TRANSMISSION OF POTATO LEAFROLL VIRUS TO PHYSALIS FLORIDANA BY 1, 5, AND 10 INOCULATIVE MYZUS PERSICAE PER PLANT GIVEN AN INOCULATION ACCESS OF 60 2 MINUTES

\begin{tabular}{|c|c|c|c|c|c|c|c|c|}
\hline \multirow{3}{*}{ Trial number } & \multirow{2}{*}{\multicolumn{3}{|c|}{$\begin{array}{l}\text { Number of aphids found on } \\
25 \text { plants at the end of } \\
\text { inoculation access out of } \\
n \text { per plant }\end{array}$}} & \multicolumn{5}{|c|}{ Percentage transmission in case of $n$ aphids per plant } \\
\hline & & & & \multirow[b]{2}{*}{1} & \multicolumn{2}{|c|}{5} & \multicolumn{2}{|c|}{10} \\
\hline & $n=1$ & 5 & 10 & & Obs. & Exp.* & Obs. & Exp. \\
\hline 1. & 24 & 113 & 223 & $16.0 \dagger$ & 60.0 & $(58.2)$ & 96.0 & $(82.5)$ \\
\hline $2 \ddagger \ldots$ & 8 & 28 & 83 & 4.0 & 24.0 & $(18.5)$ & 36.0 & $(33.5)$ \\
\hline $3 \ldots \ldots \ldots \ldots \ldots \ldots$ & 16 & 69 & 116 & 28.0 & 76.0 & $(80.7)$ & 88.0 & $(96.3)$ \\
\hline $4 \ldots \ldots \ldots \ldots \ldots \ldots$ & 22 & 87 & 141 & 52.0 & 84.0 & $(97.5)$ & 88.0 & $(99.9)$ \\
\hline $5 \ldots \ldots \ldots \ldots \ldots \ldots$ & 12 & 86 & 149 & 36.0 & 92.0 & $(89.3)$ & 100.0 & $(98.9)$ \\
\hline A verage per cent. & 65.6 & 61.3 & 57.0 & 27.2 & 67.2 & $(68.8)$ & 81.6 & $(80.2)$ \\
\hline
\end{tabular}

* Figures in parentheses represent expected percentage transmission calculated according to the binomial theorem, taking $p=$ observed transmission by single aphids.

Each figure is based on 25 plants inoculated.

$\ddagger$ High mortality of aphids in trial 2 was due to poisoning from cages which had been fumigated with nicotine the day before the trial.

insects would be less than 100 per cent. Two experiments, (1) using 1, 5, and 10 inoculative Myzus persicae per plant given an inoculation access for $60 \pm 2$ minutes, and (2) using 1,2,3,4, and 5 aphids per plant allowed $30 \pm 1$ minutes' inoculation access, were conducted.

Transmission by 1, 5, and 10 Aphids per Plant During a $60 \pm 2$ Minutes' Inoculation Access Period. Myzus persicae reared on Physalis floridana infected with potato leafroll virus were collected in an aspirator and put at random into small plastic cages $(23 \mathrm{~mm}$ long and $16 \mathrm{~mm}$ in diameter with nylon net at one end and a cork at the other) in lots of 1,5 , and 10 . When 25 cages for each of the three lots were ready, the aphids were shaken onto the nylon end by tapping at the cork; the cork was removed; the cage was inverted over cotyledon stage $P$. floridana and pressed slightly into the soil. Plants had been labeled at random previously. When all the cages were placed in position, taking one cage of each lot at a time, the aphids still on the nylon mesh were stroked with a camel's-hair brush to make them drop in 
the vicinity of the plant. The aphids were removed after $60 \pm 2$ minutes and the number of aphids found on the plants recorded. Five such trials were conducted using a total of 125 plants for each treatment. In each trial 25 uninoculated plants were included as check. None of these became infected.

An examination of the results (table 12) shows that when the actual percentage of transmission in each of the five trials in case of 5 and 10 aphids per plant was compared with expected values of transmission calculated on the basis of transmission by corresponding single insect, using the binomial theorem, in 6 out of 10 cases the actual values were higher than expected ones, and the average of actual and expected values was in close agreement indicating that the deviations could be attributed to chance. In the four cases in which actual transmission values failed to obtain the expected levels (trials 3 and 4), the percentage of aphids found on the plants at

TABLE 13

TRANSMISSION OF POTATO LEAFROLL VIRUS TO PHYSALIS FLORIDANA BY 1, 2, 3, 4, AND 5 INOCULATIVE MYZUS PERSICAE PER PLANT GIVEN AN INOCULATION ACCESS PERIOD OF $30 \pm 1$ MINUTES

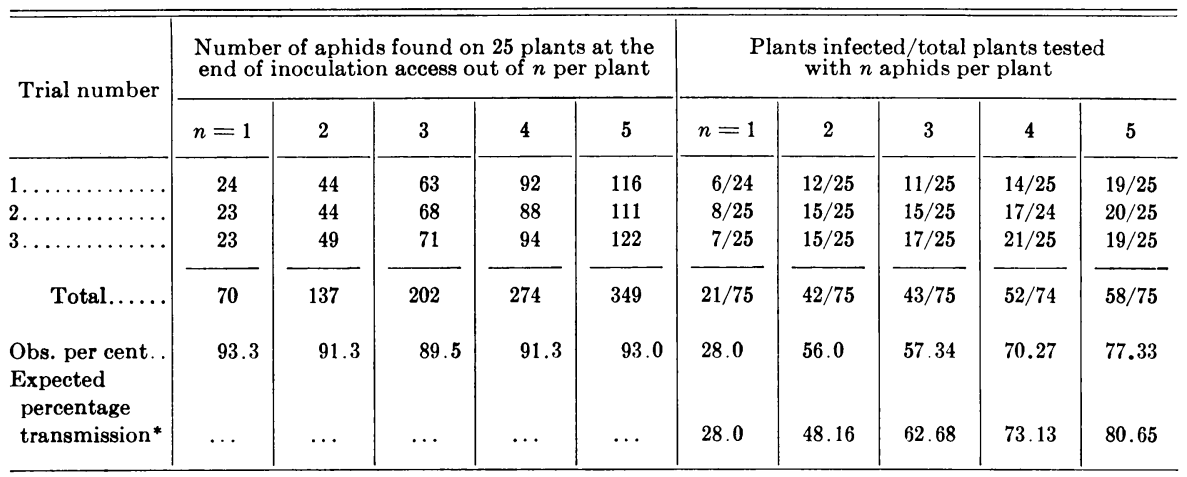

* Chi square value for observed versus expected percentage transmission $=3.3686$, d.f. $=3, p=>0.30$.

the end of the inoculation access period was considerably lower than that in case of corresponding single insects. Lower actual transmission than expected in these cases was, therefore, perhaps due to lesser numbers of aphids feeding on the test plants during the inoculation access period.

On the other hand, if the expected values of transmission for groups of 5 and 10 aphids per plant were calculated using $p=0.272$, representing the average transmission by single aphids, these figures (79.55 and 95.82 per cent) would be considerably higher than the actual values, 67.2 and 81.6, respectively. This use of an average percentage transmission by single insects would be suspect in view of the fact that four cases of depressed actual values over calculated expected ones reversed the effect of six cases in which the results were just the opposite.

Transmission by 1, 2, 3, 4, and 5 Aphids Per Plant During a $30 \pm 1$ Minutes' Inoculation Access Period. Inoculative green peach aphids were collected in an aspirator and placed on previously randomly labeled test plants of a row consisting of one plant for each treatment, starting from 
one end and proceeding to the other. The aphids were confined to the test plants by using plastic cages $(23 \mathrm{~mm} \times 16 \mathrm{~mm})$. Each plant received 1 to 5 aphids, or none in case of an equal number of check plants none of which became infected. The aphids were removed after $30 \pm 1$ minutes and the number of aphids found on the plant recorded. Each trial consisted of 25 plants per treatment and three such trials were run.

Table 13 shows that the numbers of aphids found on plants at the end of inoculation access period in each treatment were roughly in proportion to the total numbers placed on them if totals of the three trials were considered. It further shows that actual values of percentage transmission by groups of 2 to 5 aphids per plant were in agreement with expected values calculated by using binomial theorem and taking $p=0.28$, which was the actual percentage transmission by single aphids $\left(x^{2}=3.368\right.$, d. f. $\left.=\mathrm{n}-2=3, \mathrm{p}>0.30\right)$.

Thus, in both the above experiments, i.e., (1) comparing transmission by 1,5 , and 10 aphids per plant given $60 \pm 2$ minutes' inoculation access, and (2) comparing transmission by $1,2,3,4$, and 5 aphids per plant given $30 \pm 1$ minutes' inoculation access, the actual values of transmission were generally in agreement with those expected under binomial assumptions, using observed value of $p$ for single aphids for the computations.

\section{Effect of Number of Inoculative and Noninoculative Myzus persicae on Transmission of Potato Leafroll Virus}

In a series of seven trials, transmission of potato leafroll virus to Physalis floridana by $0,1,5$, and 10 inoculative aphids per plant was studied together with transmission by single inoculative aphids when grouped with 4 and 9 noninoculative aphids; and 5 inoculative aphids grouped with 5 and 10 noninoculative ones. The aphids were given 48 hours of access time on the test plants. The results are given in table 14. As in a similar previous series (table 11, page 297), the actual value of transmission was lower than the expected value in case of groups of 5 inoculative aphids per plant, and again with 10 inoculative aphids per plant there was no deviation of the actual value from the expected one.

Combining 4 noninoculative aphids with 1 inoculative aphid, and 5 noninoculative aphids with 5 inoculative aphids per plant did not show any adverse effect upon transmission; instead there was a trend in the opposite direction in the latter case. However, when 9 noninoculative aphids were combined with 1 inoculative aphid, and when 10 noninoculative aphids were grouped with 5 inoculative aphids there was some tendency for the transmission to be lower than when only 1 or 5 inoculative aphids, respectively, were used for transmission.

\section{Attempts to Determine the Influence of Feeding of Myzus persicae for Varying Periods Prior to Inoculation upon the Resistance of Physalis floridana to Infection with Potato Leafroll Virus}

To test the effect of feeding of aphids on the resistance of Physalis floridana to systemic infection with potato leafroll virus, noninoculative Myzus per- 


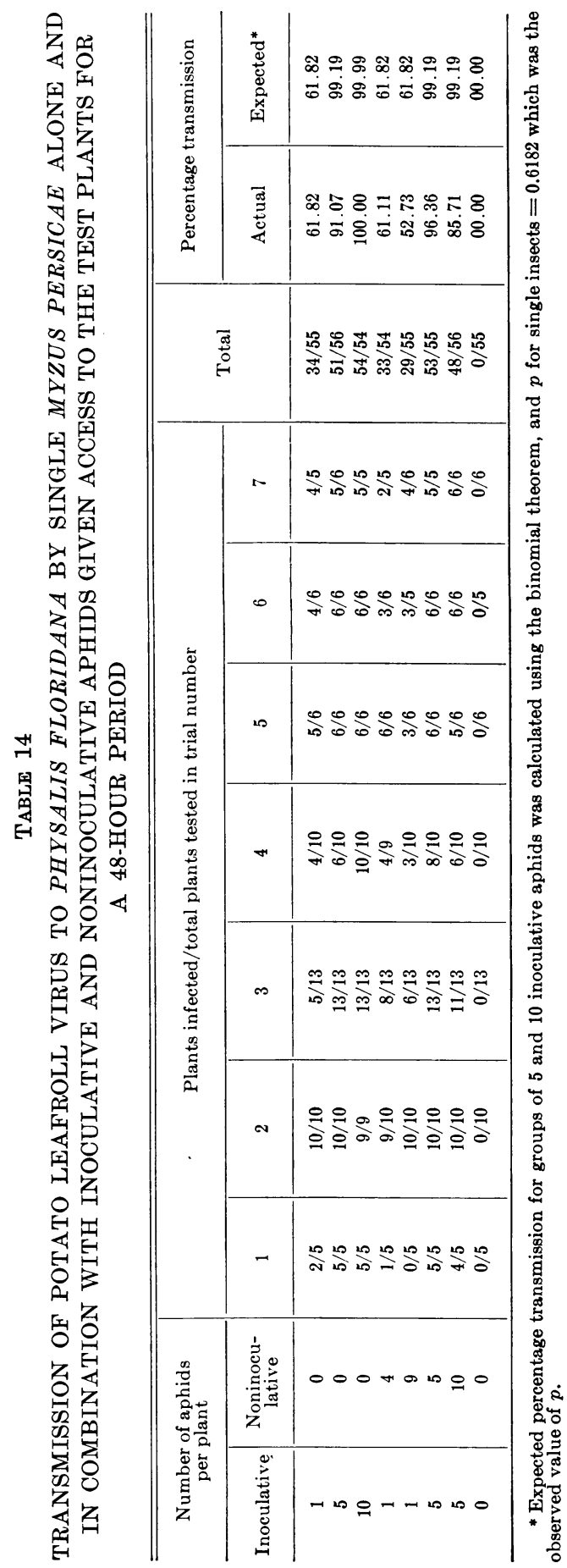


sicae were allowed to feed on a set of $P$. floridana plants for a given period prior to inoculation. Such plants are hereafter called 'pretreated' plants. As a check, a similar set of plants was caged under identical conditions but no aphids were allowed to feed on these prior to inoculation, and such plants are, hereafter, referred to as 'nonpretreated' plants. A third set of similar plants was neither fed upon by noninoculative aphids nor inoculated, but was otherwise kept under identical conditions, and is designated as 'check.' The noninoculative aphids were allowed feeding access to: (1) the whole plant in some experiments, and (2) only a portion of a leaf in others.

A. Noninoculative Aphids Allowed Feeding Access to All Aerial Parts of Plants. The Physalis floridana plants used were in cotyledon stage. Ten noninoculative aphids were placed on each plant, and confined to it by a glass tube. In all but one experiment, these were reared on mustard. At the end of the desired length of aphid feeding (pretreatment) all the surviving aphids were removed with an aspirator. Each of the pretreated and nonpretreated plants was exposed to inoculation by 1 inoculative aphid reared on $P$. floridana infected with leafroll virus allowing access to the plants for 48 hours. Pretreatment lasting four, five, and seven days was tested running three, three, and two trials, respectively.

In the first two trials testing the effect of five days of pretreatment the dead noninoculative aphids were replaced by fresh ones three days after the pretreatment began. In the third trial the noninoculative aphids used were reared on Physalis floridana. The mortality of these aphids on the test plants, $P$. floridana, was slightly lower than of those reared on mustard, but still most were dead by the end of five days. Unlike the first two trials, the dead aphids were not replaced. In the trials to test the effect of seven days of pretreatment, the aphids that died during pretreatment were replaced by fresh ones after two, four, and six days in the first trial, and after three and four days in the second.

B. Noninoculative Aphids Allowed Access to a Part of a Leaf. Physalis floridana plants in three- to four- leaf stage were used for two experiments. Ten noninoculative aphids per plant were confined to a small leaf area (42 sq $\mathrm{mm}$, approximately) on the upper surface of a set of plants using a gelatincapsule leaf-cage. In both experiments all the aphids were found dead after three days. The dead aphids were removed, and the plants inoculated immediately in one experiment, but 10 additional noninoculative aphids per plant were allowed to feed for one more day in the second experiment before inoculation was made. Inoculation of the pretreated plants was effected by confining single Myzus persicae for five hours on each plant to the same area on which noninoculative aphids had fed. Identical leaf-cages without any aphids were applied to each of an equal number of similar plants for the duration of pretreatment after which 1 inoculative $M$. persicae was confined in each cage in situ for a period of five hours in order to inoculate the nonpretreated plants. The inoculative aphids used were reared on $P$. floridana infected with potato leafroll virus.

A total of 10 trials was conducted using the two techniques, namely, allowing noninoculative aphids to feed on (1) all aerial parts of the plant, and (2) only a part of one leaf, in order to study the influence of varying 
periods of feeding by Myzus persicae prior to inoculation, on the resistance of Physalis floridana to infection with potato leafroll virus. The results, reported in tables 15 and 16 , show a trend for the pretreated plants to be less successfully inoculated than nonpretreated ones. However, in the experiments in which the pretreatment lasted for four, five, and seven days prior to inoculation, only with five-days' pretreatment was the evidence of decrease in transmission of significance $\left(35 / 61\right.$ versus $49 / 56$; adj. $\chi^{2}=11.78$, d. f. $=1$, $\mathrm{p}=<0.01)$. If the total figures are used $(76 / 136$ versus $105 / 136)$ a simple chi square test would yield significant evidence, but a failure for the transmission to remain constant within the treatments (adj. $\chi^{2}=13.88$, d. f. $=1$, $p \approx 0.02$, when testing the pretreated series for homogeneity) would lessen the reliability of the evidence.

In the two trials when pretreatment was confined to single leaf (table 16), the results are even less conclusive. In the first trial (three-day pretreatment) little evidence was gained to indicate that pretreatment decreased transmission, and in the second trial the smallness of the sample prohibited statistical assessment. While combining the two would lead to statistically significant evidence, the within-treatment heterogeneity again would make its reliability uncertain.

In the two trials in which the short inoculation access period of five hours was used (table 16) no aphid died, but there were more negative plants on which the inoculative aphids did not feed in pretreated than in nonpretreated plants. In the trials employing a 48 hours' long inoculation access period inoculative aphids were found dead on some plants which failed to become infected with the leafroll virus. It is possible that in these cases the aphids did not feed at all, or fed for a very short period. In six of the seven trials in which records were kept, there were more such cases among pretreated than nonpretreated plants, the totals being 38 and 20 , respectively (table 15). These observations would indicate unfavorability of such plants for aphid maintenance.

If allowance is made for the difference in numbers of noninfected plants on which the inoculative aphids were found dead at the end of inoculation access period (or did not feed during the short inoculation access period in two experiments), in no single example of the 10 trials would the evidenee for difference in transmission between pretreated and nonpretreated plants be statistically significant although in nine of the 10 trials the adjusted figures would still be lower for pretreated than nonpretreated plants.

These small differences in transmission between pretreated and nonpretreated plants in individual trials gradually add up to a large difference. Thus, considering the totals, 50.3 per cent of 169 pretreated and 73.3 per cent of 165 nonpretreated plants became infected. Even after making an allowance for the difference in number of noninfected plants on which inoculative aphids were found dead at the end of inoculation access (table 15) or did not feed on the test plant during the short inoculation access period in case of two experiments (table 16), the evidence for the difference in totals of transmissions in the 10 trials between the two groups of plants could be judged to be highly significant (adj. $\chi^{2}=8.547$, d. f. $=1, p=<0.01$ ). Again the statistical interpretation is weakened by the interexperimental variation 
TABLE 15

INFLUENCE OF MYZUS PERSICAE FEEDING FOR VARYING PERIODS PRIOR TO INOCULATION ON THE TRANSMISSION OF POTATO LEAFROLL VIRUS TO PHYSALIS FLORIDANA BY SINGLE M. PERSICAE DURING A 48 HOURS' INOCULATION ACCESS PERIOD

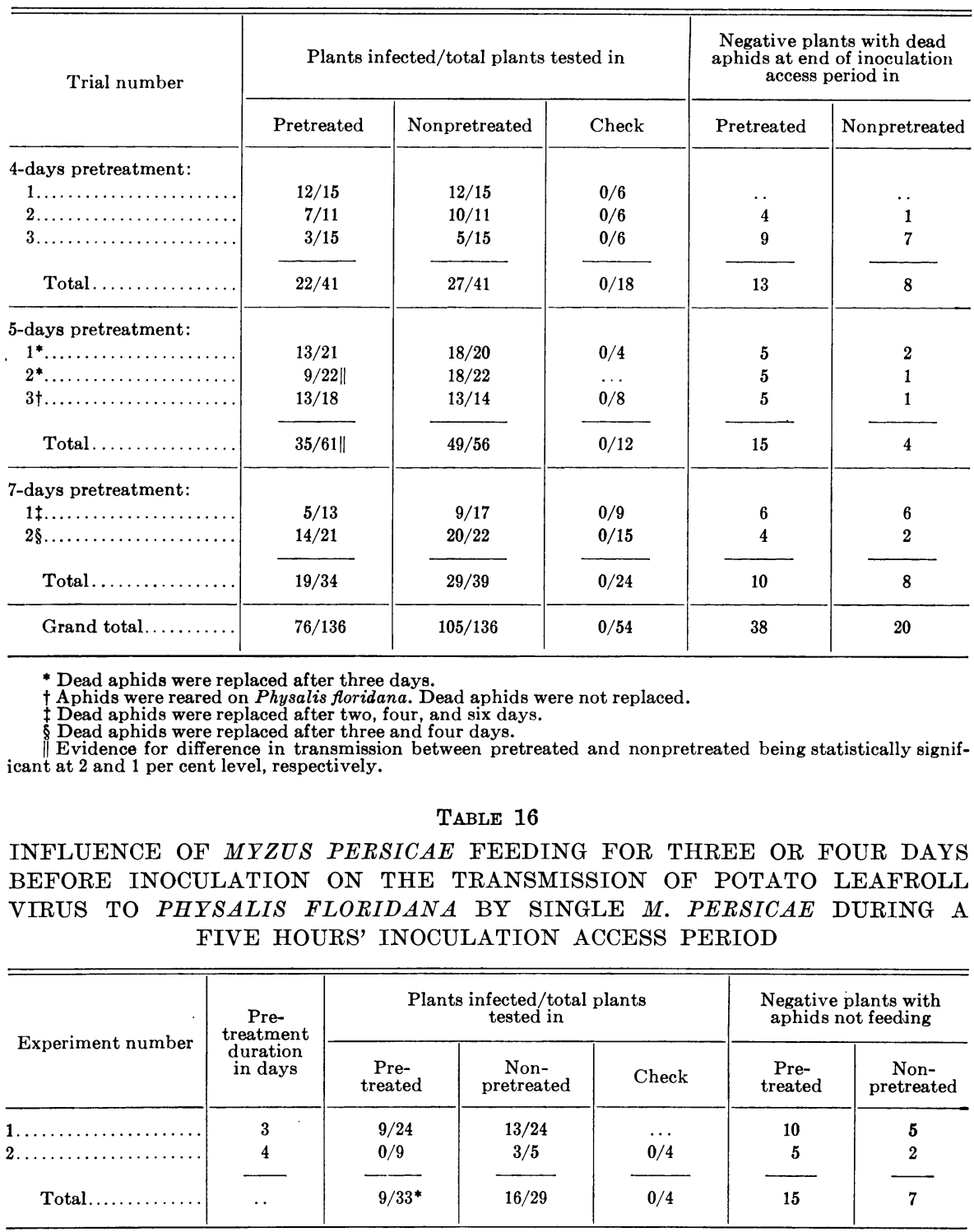

* Adj. chi sq. $=3.88$, d.f. $=1 ;$ but adj. chi sq. $=1.35$ only when an adjustment is made for aphids not feeding and failing to inoculate the test plant. 


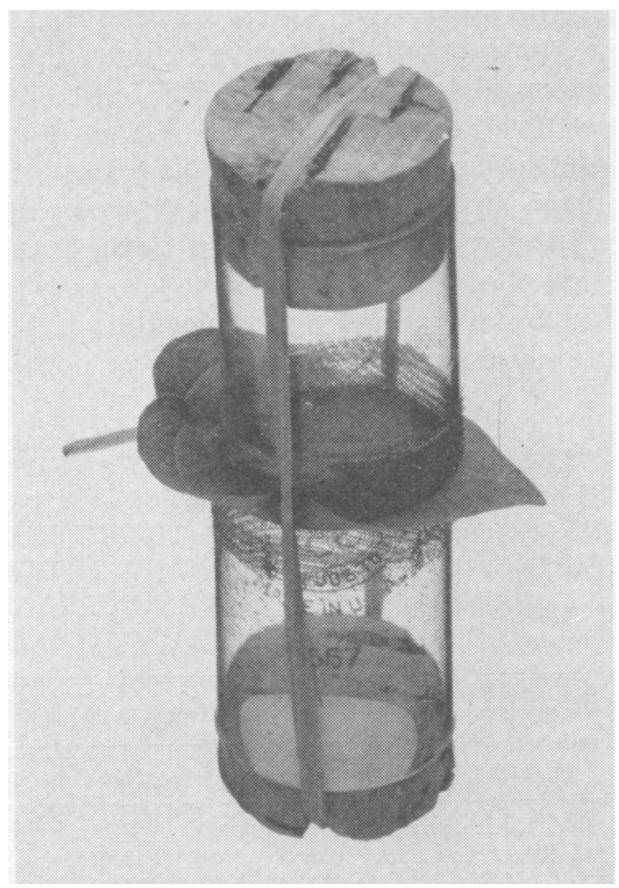

Fig. 6. Method of fixing two plastic cages onto a leaf to allow inoculative and noninoculative $M$. persicae feeding access to the opposite surfaces of the same leaf area concurrently but without interference.

in percentage transmission in both pretreated and nonpretreated groups of plants. Despite this, however, the results described above could be given in support of the statement that feeding by large numbers of Myzus persicae for prolonged periods prior to inoculation tended to reduce the numbers of Physalis floridana plants which became infected with potato leafroll virus. Whether this is due to a reduction in plant susceptibility, or is due to a tendency for the inoculative aphids to fail to feed normally upon the pretreated plants (or leaves) is not known, for the results can be interpreted as supporting both ideas.

\section{Attempts to Determine the Influence of Feeding by Noninoculative Myzus persicae on Physalis floridana, During a Long Inoculation Access Time, upon the Transmission of Potato Leafroll Virus by Single Myzus persicae}

Some evidence was gained which might be interpreted as supporting the hypothesis that there is a reduction in susceptibility of Physalis floridana, to systemic infection with potato leafroll virus by Myzus persicae as a result of feeding by large numbers of noninoculative $M$. persicae for prolonged periods prior to inoculation. A series of trials was carried out in an attempt 
to determine the influence of noninoculative $M$. persicae feeding concurrently with the inoculative aphid but without interfering with the latter during a long inoculation access period.

Twenty noninoculative and 1 inoculative Myzus persicae were allowed feeding access on the lower and upper surface, respectively, of the same area of a leaf of a three- to four-leaf stage plant. To achieve this, the plastic leaf-cages containing the aphids were applied to the leaf as shown in figure 6 . The 'check' consisted of an empty cage on the lower surface and a cage with an inoculative aphid on the upper one. Inoculation access period lasted seven days. Absolute checks consisting of plants on which no aphids were

TABLE 17

EFFECT OF 20 NONINOCULATIVE MYZUS PERSICAE FEEDING ON LOWER SURFACE OF LEAF UPON THE TRANSMISSION OF POTATO LEAFROLL VIRUS TO PHYSALIS FLORIDANA BY SINGLE M. PERSICAE DURING A SEVEN DAYS' CONCURRENT ACCESS ON THE UPPER SURFACE OF THE SAME LEAF AREA

\begin{tabular}{|c|c|c|c|}
\hline \multirow{2}{*}{ Trial number } & \multicolumn{3}{|c|}{ Plants infected/total plants tested } \\
\hline & Treated & Check & Absolute check \\
\hline $1 \ldots$ & $13 / 20$ & $13 / 19$ & $0 / 20$ \\
\hline $2 \ldots \ldots \ldots \ldots \ldots \ldots \ldots \ldots \ldots \ldots \ldots$ & $12 / 20$ & $18 / 20$ & $0 / 20$ \\
\hline $3 \ldots \ldots \ldots \ldots \ldots \ldots \ldots \ldots \ldots$ & $17 / 25$ & $18 / 26$ & $0 / 25$ \\
\hline $4 \ldots \ldots \ldots \ldots \ldots \ldots \ldots \ldots \ldots \ldots \ldots \ldots$ & $14 / 25$ & $14 / 25$ & $0 / 25$ \\
\hline $5 \ldots \ldots \ldots \ldots \ldots \ldots \ldots \ldots \ldots \ldots \ldots \ldots \ldots \ldots$ & $10 / 25$ & $10 / 25$ & $0 / 25$ \\
\hline Total......... & $66 / 115^{*}$ & $73 / 115$ & $0 / 115$ \\
\hline
\end{tabular}

*Adj. chi square value for total of treated versus check $=0.656$, d.f. $=1, p=>0.30$.

allowed feeding access were also run. These three treatments were each applied to 115 plants in five trials. The results are given in table 17.

In none of the five trials was the evidence for difference in transmission between 'treated' plants (plants on which noninoculative aphids were allowed feeding access) and checks statistically significant at 5 per cent level, and in only one case could it be said that there was a trend for reduced susceptibility among the treated plants. Thus, although feeding by large numbers of noninoculative aphids over prolonged periods prior to inoculation in the previous experiment tended to result in fewer Physalis floridana plants becoming systemically infected with potato leafroll virus, the present test (in which noninoculative aphids fed concurrently with an inoculative one) failed to support such a trend.

\section{The Nature of Effect of Prolonged Feeding by Large Numbers of Noninoculative Myzus persicae on $\mathbf{P h y s a l i s}$ floridana}

Some evidence has been accumulated to show that feeding by large numbers of Myzus persicae upon Physalis floridana for prolonged periods prior to inoculation tends to reduce the numbers of transmissions of aphid-borne 
potato leafroll virus to this plant. The following experimental work was done in an attempt to answer the questions: (1) How long does this "inhibitory" effect of aphid feeding last? (2) Is it a local or a systemic effect?

(1) How Long Does the 'Inhibitory' Effect of Prolonged Aphid Feeding Prior to Inoculation Last? Ten noninoculative Myzus persicae per plant were given access to cotyledon stage Physalis floridana plants using glass tubes, for approximately five days. Dead aphids were replaced on the third day. One half of these pretreated plants and nonpretreated ones (plants to which no noninoculative aphids were given access) were tested with single inoculative aphids allowed a five hours' inoculation access immediately at

TABLE 18

FFFECT OF FEEDING BY NONINOCULATIVE MYZUS PERSICAE FOR FIVF DAYS (PRETREATMENT) IMMEDIATELY OR ONE WEEK BEFORE INOCULATION OF POTATO LEAFROLL VIRUS ON ITS TRANSMISSION TO PHYSALIS FLORIDANA BY SINGLE M. PERSICAE ALLOWED FIVE HOURS' INOCULATION ACCESS

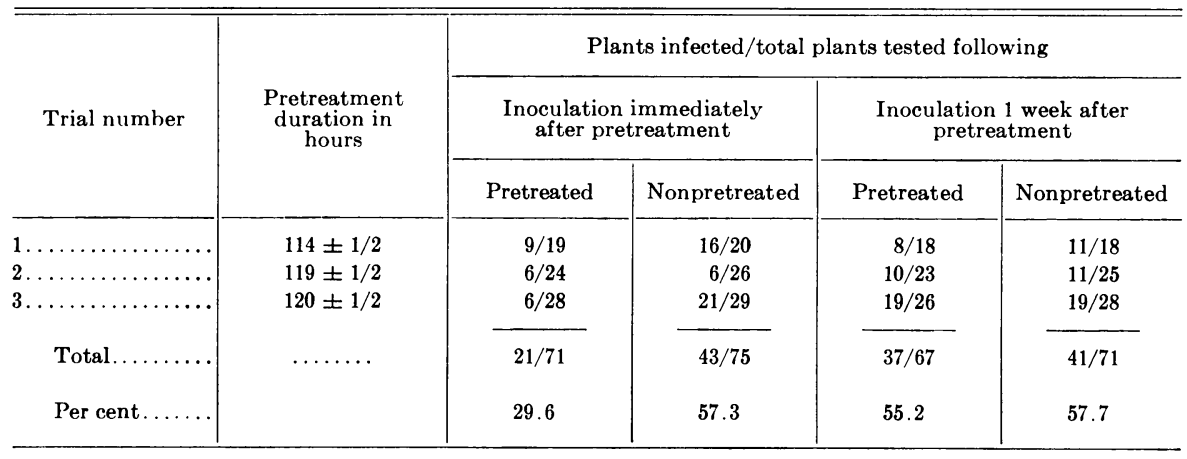

Note: Checks consisted of equal numbers of uninoculated plants. None of these became infected.

the end of aphid feeding or pretreatment duration. The other half of the plants were similarly inoculated after waiting for seven days. Adequate checks consisting of noninoculated plants were run.

The results (table 18) show that in two of the three trials fewer infections resulted among pretreated plants than among nonpretreated ones following inoculation immediately at the end of pretreatment. Failure of the aphids to be highly inoculative made the second trial too heterogeneous to be included in a chi square test of the total, but combining the results of trials 1 and 3 , the evidence for less transmission to the pretreated plants immediately inoculated is highly significant (adj. $\chi^{2}=16.78$, d. f. $=1, p=<0.001$ ). This corroborated the results obtained earlier. The evidence for difference in transmission between pretreated and nonpretreated plants following inoculation carried out one week after the end of aphid feeding was not significant in all the three trials, the difference in the totals being only 2.5 per cent.

In a later experiment, the pretreatment was extended to seven days and each lot of pretreated and nonpretreated plants was divided into three equalsized sub-lots. One lot of each kind was inoculated immediately after pretreatment, another two days later, and the third one six days later. Checks 
were also run. The results are given in table 19. In this instance, no evidence was obtained that pretreatment reduced the probability of successful transmission, and thus the previous results could not be confirmed.

The results in total indicated that any 'virus inhibitory effect' of feeding by aphids on Physalis floridana for a five- to seven-day period prior to inoculation was elusive and ephemeral to say the least.

(2) Can Either a Local or Systemic 'Virus Inhibitory Effect' of Prolonged Aphid Feeding Prior to Inoculation Be Demonstrated? Ten noninoculative Myzus persicae were allowed feeding access for five days on a leaf of each of a set of four-leaf stage Physalis floridana plants using a gelatin-capsule leaf-cage. The dead aphids were replaced on the third day.

TABLE 19

EFFECT OF FEEDING BY NONINOCULATIVE MYZUS PERSICAE FOR SEVEN DAYS (PRETREATMENT) IMMEDIATELY, TWO DAYS OR SIX DAYS BEFORE INOCULATION OF POTATO LEAFROLL VIRUS ON ITS TRANSMISSION TO PHYSALIS FLORIDANA BY SINGLE M. PERSICAE GIVEN AN INOCULATION ACCESS FOR FIVE HOURS

\begin{tabular}{|c|c|c|c|c|c|c|}
\hline \multicolumn{7}{|c|}{ Plants infected/total plants tested } \\
\hline \multirow{2}{*}{\multicolumn{2}{|c|}{$\begin{array}{l}\text { Plants inoculated immedi- } \\
\text { ately after pretreatment }\end{array}$}} & \multirow{3}{*}{ Check } & \multicolumn{4}{|c|}{ Days between pretreatment and inoculation } \\
\hline & & & \multicolumn{2}{|c|}{ Two days } & \multicolumn{2}{|c|}{ Six days } \\
\hline Pretreated & Nonpretreated & & Pretreated & Nonpretreated & Pretreated & Nonpretreated \\
\hline $17 / 25$ & $17 / 25$ & $0 / 25$ & $14 / 25$ & $21 / 25$ & $12 / 25$ & $13 / 25$ \\
\hline
\end{tabular}

These pretreated plants and an equal number of nonpretreated plants (ones on which no aphids fed but an empty gelatin-capsule leaf-cage was fixed during the pretreatment period) were inoculated by giving a five hours' inoculation access by 1 inoculative $M$. persicae per plant, in the same cage in situ or on another but younger leaf. Checks consisting of noninoculated plants were also run. The results are given in table 20 .

As in some of the earlier experiments, fewer infections resulted among pretreated than nonpretreated in all the cases. However, the difference in transmission between these two kinds of plants was much larger following inoculation at the same site where noninoculative aphids were confined during pretreatment than following inoculation on a leaf on which no noninoculative aphids had fed. Thus, considering the totals of the two experiments, the evidence for the difference in transmission between pretreated and nonpretreated plants following inoculation at the site of feeding by noninoculative aphids was statistically significant at 5 per cent level, but the difference in transmission between pretreated and nonpretreated plants following inoculation on a leaf other than the one on which noninoculative aphids fed did not have any statistical support (adj. $\chi^{2}=0.2494$, d. f. $=1$, $\mathrm{p}=>0.60)$. These results indicate that any inhibition to virus transmission by prolonged feeding of noninoculative Myzus persicae prior to inoculation tended to be localized in the area of feeding. 


\section{Attempts to Find the Effect of Feeding on Physalis floridana by Some Insects Other Than Myzus persicae, for Prolonged Periods Prior to Inoculation, upon the Susceptibility of This Plant to Infection with Potato Leafroll Virus}

Some of the previous experiments have indicated that feeding by large numbers of the green peach aphid, Myzus persicae (Sulz.), for prolonged periods prior to inoculation, reduced the success with which Physalis floridana can be inoculated with aphid-borne potato leafroll virus. Some experiments were carried out to find whether or not feeding by some other insects, viz., Myzus circumflexus (Buckton), M. ornatus Laing, Rhopalosiphum

TABLE 20

TRANSMISSION OF POTATO LEAFROLL VIRUS BY SINGLE MYZUS PERSI. $C A E$ GIVEN AN INOCULATION ACCESS FOR FIVE HOURS, AS AFFECTED BY FEEDING BY NONINOCULATIVE M. PERSICAE FOR FIVE DAYS PRIOR TO INOCULATION DIRECTLY ON THE SITE EXPOSED TO INOCULATION OR ON A LEAF OLDER THAN THE ONE EXPOSED TO INOCULATION

\begin{tabular}{|c|c|c|c|c|}
\hline \multirow{2}{*}{$\begin{array}{l}\text { Trial } \\
\text { number }\end{array}$} & \multirow{2}{*}{$\begin{array}{l}\text { Relation of inoculation site to } \\
\text { pretreated site }\end{array}$} & \multicolumn{3}{|c|}{ Infected plants/total plants tested in } \\
\hline & & Pretreated & Nonpretreated & Check \\
\hline \multirow[t]{2}{*}{1} & Same site.............. & $3 / 12$ & $8 / 12$ & $0 / 25$ \\
\hline & Older leaf................ & $8 / 13$ & $9 / 13$ & $\ldots$ \\
\hline \multirow[t]{2}{*}{2} & Saine site....... & $4 / 25$ & $9 / 25$ & $0 / 24$ \\
\hline & Older leaf $\ldots \ldots \ldots \ldots \ldots \ldots \ldots \ldots \ldots \ldots$ & $2 / 25$ & $4 / 25$ & $\cdots$ \\
\hline \multirow[t]{2}{*}{ Total } & Same site $\ldots \ldots \ldots \ldots \ldots \ldots \ldots \ldots \ldots \ldots \ldots \ldots \ldots \ldots \ldots$ & $7 / 37$ & $17 / 37^{*}$ & $0 / 49$ \\
\hline & Older leaf $\ldots \ldots \ldots \ldots \ldots \ldots \ldots \ldots \ldots \ldots$ & $10 / 38$ & $13 / 38 \dagger$ & $\ldots$ \\
\hline
\end{tabular}

${ }^{*}$ Adj. $\chi^{2}=4.995$, d.f. $=1, p=<0.05$.

$\dagger$ Adj. $\chi^{2}=0.249$, d.f. $=1, \mathrm{p}=>0.50$.

pseudobrassicae (Davis), and Macrosteles fascifrons Stål. would have similar effect, and are reported here.

Myzus circumflexus. Physalis floridana plants in cotyledon stage were exposed under glass tubes to feeding by groups of 20 noninoculative apterous $M$. circumflexus per plant for a period of seven days. The dead aphids were replaced after two and four days. Each of these pretreated plants and nonpretreated ones (plants on which no aphids were allowed feeding access) was inoculated by single inoculative Myzus persicae given an inoculation access of five hours. Checks consisted of noninoculated plants. The three treatments were repeated in four trials using a total of approximately 100 plants per treatment.

As in the case of Myzus persicae, transmissions among the pretreated plants tended to be fewer than among nonpretreated (table 21). In three out of four trials the significant evidence gained from the totals of trials 1,3 , and $4\left(\operatorname{adj} . \chi^{2}=9.9\right.$, d. f. $\left.=1, p=<0.01\right)$ was somewhat negated by the results in trial 2, where essentially equivalent transmissions occurred. Table 21 further shows that in total, there was no difference between pretreated and nonpretreated plants regarding the number of plants on which the test inoculative 
aphids were feeding at the end of inoculation access period, and also the number of negative (noninfected) plants without the inoculative aphids on them at the end of inoculation access. Thus, a difference in transmission results between pretreated and nonpretreated plants might be indicative of a decrease in susceptibility induced by prolonged feeding of large numbers of Myzus circumflexus prior to inoculation. It might be noted, however, in the trial (no. 2) in which more aphids were found feeding on pretreated plants

TABLE 21

RESULTS OF ATTEMPTS TO FIND THE EFFECT OF FEEDING ON PHYSALIS FLORIDANA BY 20 MYZUS CIRCUMFLEXUS AND M. ORNATUS PER PLANT FOR SEVEN DAYS BEFORE INOCULATION ON THE TRANSMISSION OF POTATO LEAFROLL VIRUS BY SINGLE M. PERSICAE GIVEN FIVE HOURS OF INOCULATION ACCESS

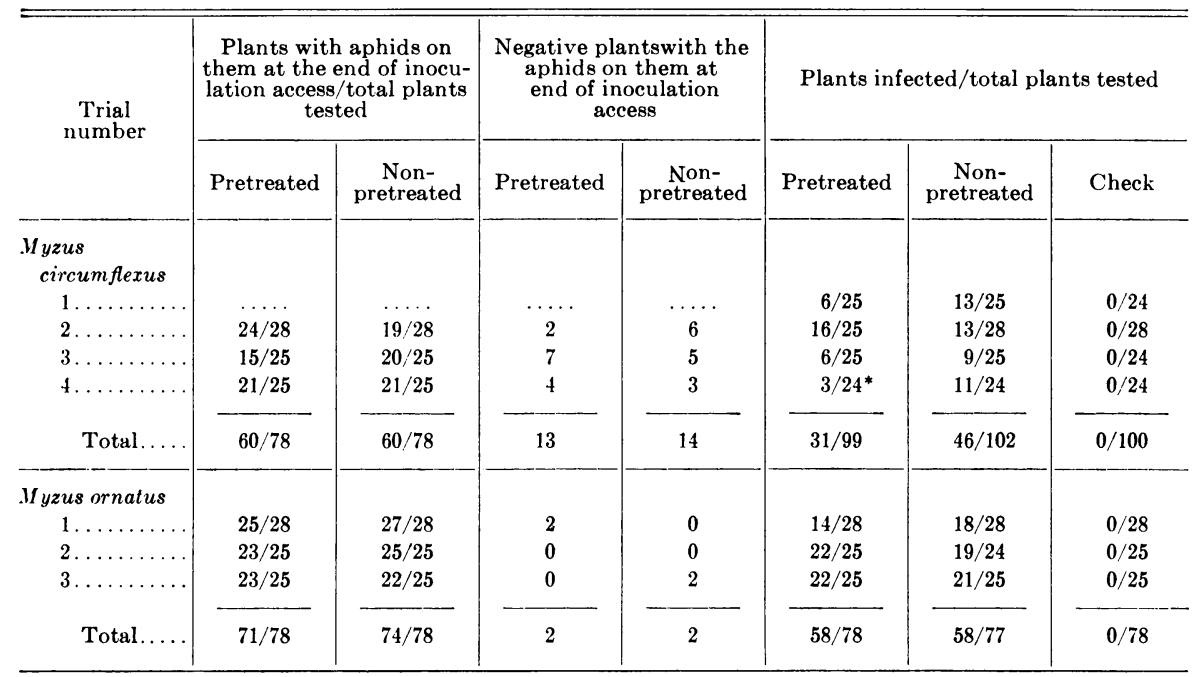

* Evidence for difference in transmission between pretreated and nonpretreated is statistically significant at the 5 per cent level.

than on nonpretreated ones, transmission was in the same order. Thus, again the possibility that aphid feeding tends to reduce the palatibility of plant tissue to subsequent feeding cannot be eliminated.

Myzus ornatus. Three trials identical with those described above for Myzus circumflexus but using $M$. ornatus instead were conducted. The results obtained (table 21) indicated no effect of feeding by this aphid species on the subsequent transmission of potato leafroll virus to Physalis floridana by single inoculative Myzus persicae apterae.

Rhopalosiphum pseudobrassicae. Three trials identical with those detailed above for Myzus circumflexus with the only exception of using 15 apterous $R$. pseudobrassicae per plant for pretreatment were carried out. The results obtained (table 22) showed little difference in transmission between pretreated and nonpretreated plants indicating that there was no effect of 
feeding by $R$. pseudobrassicae upon subsequent inoculation of Physalis floridana by aphids carrying the potato leafroll virus.

Macrosteles fascifrons. Ten noninoculative nymphs of the aster leafhopper, $M$. fascifrons, were allowed feeding access on the lower leaf surface of a four-leaf stage Physalis floridana plant for seven days prior to inoculation. The pretreated plants were then inoculated by allowing 1 inoculative Myzus persicae per plant an inoculation access of five hours on the upper surface of

TABLE 22

RESULTS OF ATTEMPTS TO FIND THE EFFECT OF FEEDING ON PHYSALIS FLORIDANA BY RHOPALOSIPHUM PSEUDOBRASSICAE AND MACROSTELES FASCIFRONS FOR SEVEN I)AYS PRIOR TO INOCULATION, ON THE TRANSMISSION OF POTATO LEAFROLL VIRUS BY SINGLE MYZUS PERSICAE GIVEN FIVE HOURS OF INOCULATION ACCESS

\begin{tabular}{|c|c|c|c|}
\hline \multirow{2}{*}{ Trial number } & \multicolumn{3}{|c|}{ Plants infected/total plants tested } \\
\hline & Pretreated & Nonpretreated & Check \\
\hline \multicolumn{4}{|l|}{ Rhopalosiphum pseudobrassicae* } \\
\hline $1 \ldots \ldots \ldots \ldots \ldots \ldots \ldots$ & $12 / 29$ & $18 / 28$ & $0 / 18$ \\
\hline $2 \ldots \ldots \ldots \ldots \ldots \ldots \ldots \ldots \ldots \ldots$ & $15 / 25$ & $13 / 25$ & $0 / 24$ \\
\hline $3 \ldots \ldots \ldots \ldots \ldots \ldots \ldots \ldots \ldots \ldots$ & $16 / 25$ & $9 / 25$ & $0 / 25$ \\
\hline Total. & $43 / 79$ & $40 / 78$ & $0 / 67$ \\
\hline \multicolumn{4}{|l|}{ Macrosteles fascifrons $\dagger^{\dagger}$} \\
\hline $1 \ldots \ldots \ldots \ldots \ldots$ & $8 / 25$ & $7 / 25$ & $0 / 25$ \\
\hline 2. & $9 / 25$ & $8 / 25$ & $0 / 25$ \\
\hline 3. & $1 / 22$ & $5 / 25$ & $0 / 25$ \\
\hline $4 \ldots \ldots \ldots$ & $7 / 24$ & $5 / 25$ & $0 / 25$ \\
\hline Total. & $25 / 96$ & $25 / 100$ & $0 / 100$ \\
\hline
\end{tabular}

* 15 Rhopalosiphum pseudobrassicae were placed on each plant in cotyledon stage, and dead ones replaced after two and four days.

$\dagger 10$ nymphs of Macrosteles fascifrons were given feeding access to each four-leaf stage plant, on lower side of a leaf using a plastic leaf-cage. Inoculative aphid was given access on the opposite side of the same leaf.

pretreated leaf. Nonpretreated plants (ones on which no insects had fed) were inoculated likewise. Checks consisted of noninoculated plants. The three treatments were compared in four trials, utilizing a total of 100 plants per treatment.

It may be seen from table 22 that percentage of transmission among pretreated and nonpretreated plants was almost equal. Thus, prolonged feeding by Macrosteles fascifrons nymphs on Physalis floridana prior to inoculation with potato leafroll virus had no effect on subsequent inoculation of this plant by aphid-borne potato leafroll virus.

Thus, of the four species, namely, Myzus circumflexus, Myzus ornatus, Rhopalosiphum pseudobrassicae, and Macrosteles fascifrons tested, only $M$. circumflexus indicated a potential effect on transmission. Thus, the effect (if it is a real effect) either is not a general effect of insect feeding, or the various species of insects show a different effect. 


\section{DISCUSSION}

The experimental results indicated that in the test plant population no plants were immune or highly resistant to systemic infection with aphidborne potato leafroll virus. Intervarietal variation in susceptibility of sugar beets to curly top infection and of potatoes to leafroll, potato virus $\mathrm{Y}$, and potato yellow dwarf viruses has been reported (Giddings, 1946; Bawden and Kassanis, 1946; Larson, 1945) but no studies seem to have been reported so far in the literature on intravarietal variation in plant susceptibility to virus infection.

Interference in feeding on the test plant during inoculation access period among individuals of a group could result in lower actual transmission by groups of insects than that expected according to the hypothesis that infections are essentially separate and independent events, if individuals of the aphid species used for transmission tended to feed in isolation but not to feed when in proximity to other individuals. No work on such an 'interference effect' in feeding during inoculation access periods seems to have been previously reported. Results of present experiments indicated that small groups of Myzus persicae did not interfere with one another while feeding during the test inoculation access periods. Thus, interference in feeding was not considered to be a factor responsible for the occasional depression of transmission by groups below that expected upon the separate and independent (binomial) hypothesis in the transmission of potato leafroll virus by $M$. persicae.

During the present investigations prolonged feeding by noninoculative Myzus persicae on the test plants prior to inoculation tended to decrease the transmission efficiency of potato leafroll virus by green peach aphids to Physalis floridana. This confirmed the report of Williams and Ross (1957) regarding the effects of feeding by $M$. persicae on Physalis angulata upon the transmission of potato leafroll virus to this plant by the green peach aphids. Of the 4 other species of insects tested, only prior feeding by Myzus circumflexus tended to produce a similar effect. In total, the tests indicated that the depression effect as could be demonstrated was rather temporary and localized in the area of previous aphid feeding. Williams and Ross (1957) interpreted the reduction in transmission to plants preconditioned by aphid feeding as a decrease in plant susceptibility, but the present data would support either a reduced susceptibility or a decreased palatability hypothesis, or both. In speculating as to an actual mechanism of such a reduction in transmission success one could suggest the following: (1) physical damage due to aphid feeding might hinder systemic movement of virus particles to suitable sites for multiplication; (2) chemical changes in plant tissue induced by salivary secretions of aphids could render the necessary materials for virus multiplication temporarily unavailable; (3) injection with the saliva of virus inhibitors and/or inactivators into the plant; (4) the plant tissue could become less palatable or attractive to inoculating insects due to secretions and/or excretions of aphids; and (5) loss in turgidity of the plant tissue due to aphid feeding resulting in conditions unsuitable for virus transportation and/or multiplication. However, a simple loss of turgidity was 


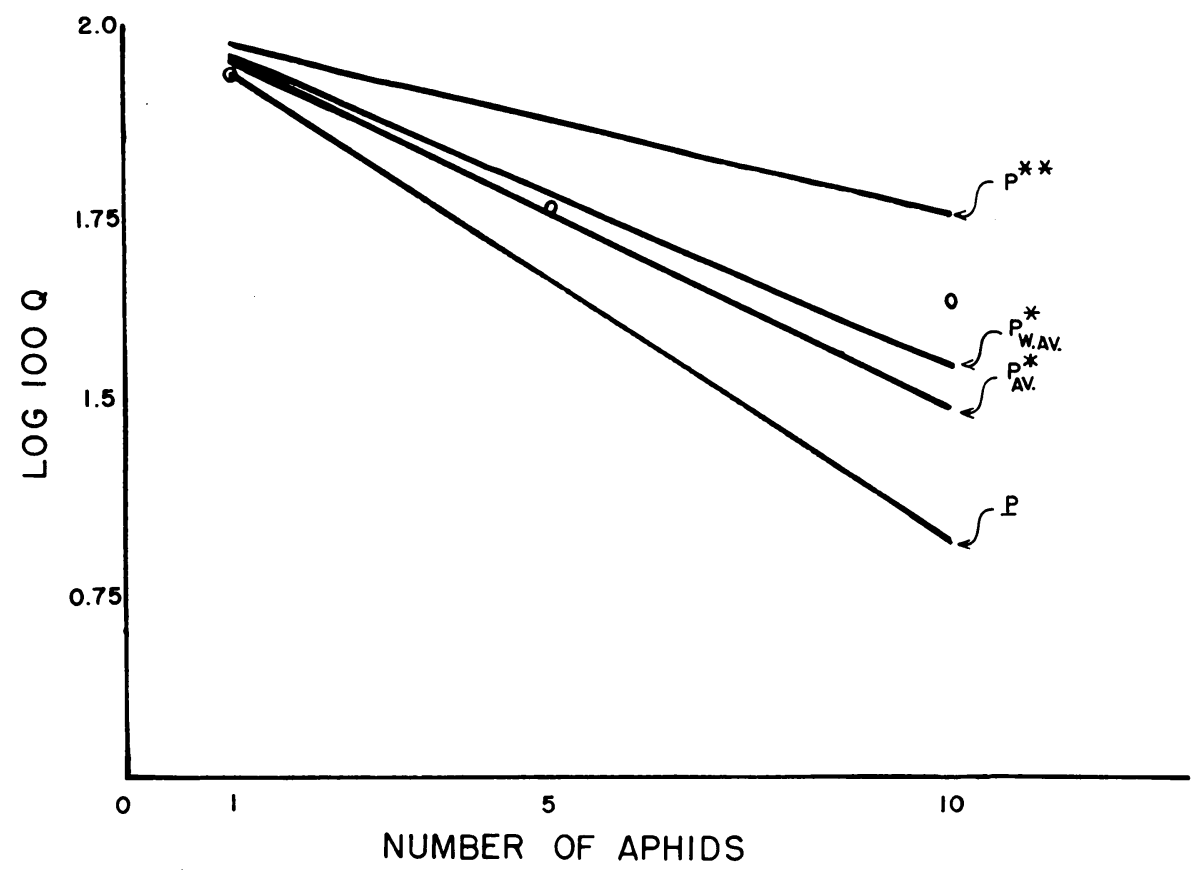

Fig. 7. Observed results (using the relation $Q=1-\mathrm{P}$ ) of transmission by 1,5 , and 10 $M$. persicae per plant compared with transmission expectancies as calculated using different values of $p: p=$ observed probability of transmission by single aphids, $\mathrm{p}^{*}{ }_{\mathrm{nv}} .=$ average of the maximum likelihood estimate of $\mathrm{p}, \mathrm{p}^{*}{ }_{\mathrm{w} . \mathrm{av}}=$ weighted average of the maximum likelihood estimate of $p, p^{* *}=$ total plants infected in case of single and multiple aphids per plant divided by the total number of aphids used.

found not to depress transmission efficiency in limited tests. Lock's (1954) work on aphid damage to plants caused by feeding activities might be used to provide partial support for the hypothesis at (1) above. However, further experimental work designed specifically to test these various suggestions would be needed before one could claim evidence for accepting or rejecting any one or a combination of them.

Nevertheless, the test on: (1) the effects of aphid feeding concurrently with inoculative aphids but without interfering with them, and (2) the effects of duration of inoculation access period upon transmission strongly suggest that limited 'aphid feeding' is not a major factor responsible for the occasional reported lower values of transmission efficiency for groups of 5 and 10 aphids per plant unless the virus charge per individual aphid and/or the percentage of inoculative individuals among aphids used for inoculation were very low. This could be true in case of Williams' (1957, unpublished thesis) work (tables 24 and 25) in which transmissions by single insects varied from 0 to 10.5 per cent only.

As pointed out by Sylvester (1956) there are several methods of estimating the value of $p$, the probability of transmission by single insects: (1) for single insects $p$ ( $=\mathrm{P}_{\text {obs. }}$ for single insects) can be estimated by dividing 


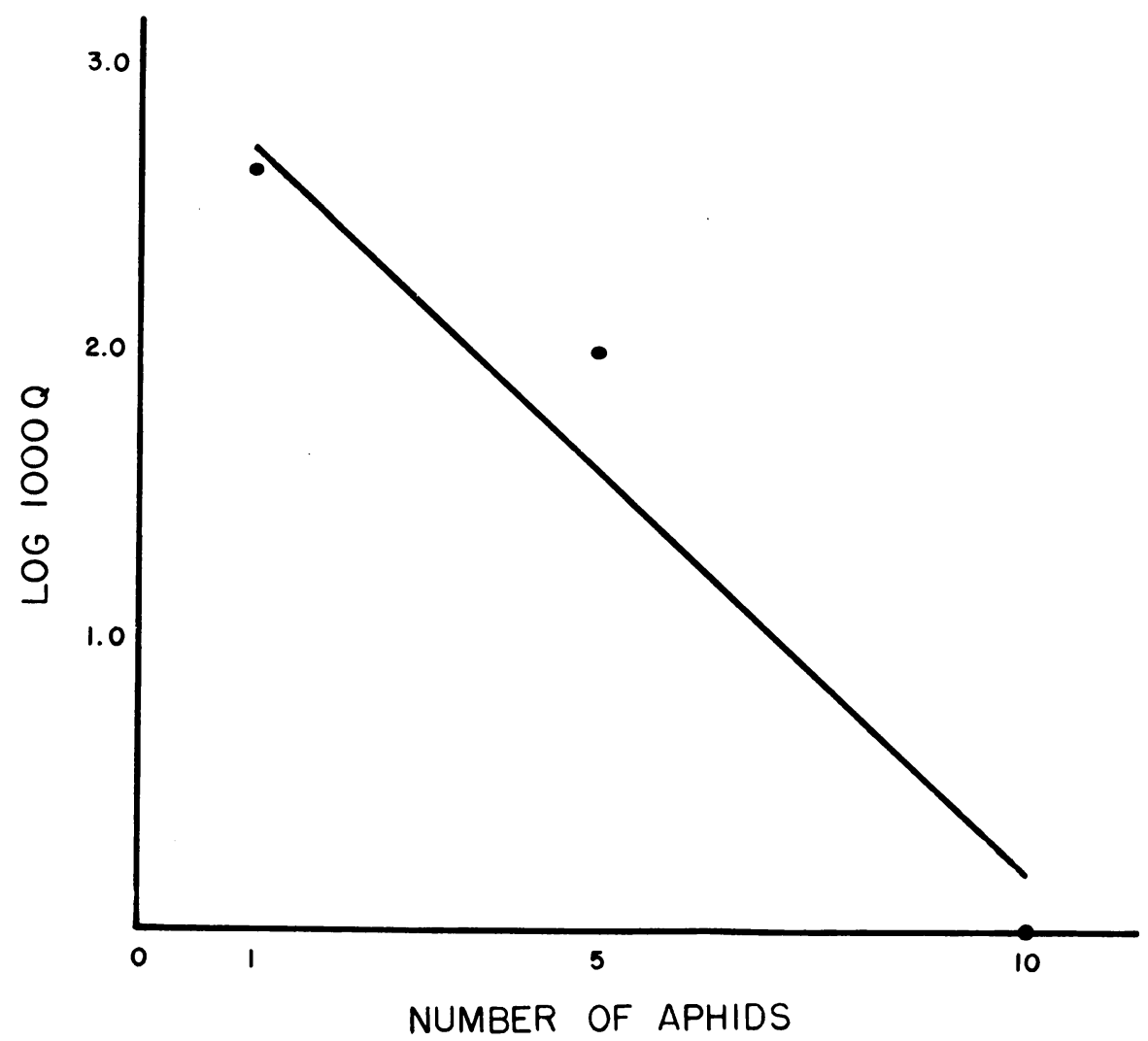

Fig. 8. Transmission results based on $\mathrm{p}^{*}{ }_{\text {av. }}$ (average of maximum likelihood estimates of $p$ for 1 and 5 aphids per plant) and points of observed values from data in table 11. The point on the $\mathrm{X}$ axis represents $Q=0.0000$.

the number of infections produced by one insect per plant, by the total number of plants inoculated; (2) a maximum likelihood estimate of $\mathrm{p}\left(\mathrm{p}^{*}\right)$ may be obtained from multiple aphid transmissions, viz., $\mathrm{p}^{*}=1-{ }^{\mathrm{n}} \vee \mathrm{Q}$, where $Q$ is the probability of nontransmission by a group of $n$ insects per plant, assuming that transmissions by individuals of a colony were independent events; and (3) the total number of plants infected can be divided by the total number of insects used in a series of transmission tests using single and multiple aphids to give another estimate $\left(\mathrm{p}^{* *}\right)$ of $\mathrm{p}$. The last method tends to depress the estimate of $p$, especially if the multiple aphid groups that resulted in 100 per cent transmission are included, since an increase in aphid numbers per plant beyond the minimum necessary to produce the maximum (100 per cent) infection cannot result in any higher transmission. Such an estimate, therefore, is not satisfactory.

In tests using single and multiple insects, the average of $\mathrm{p}^{*}\left(\mathrm{p}^{*}\right.$ av. $)$ should be a better estimator than $p$ for the purposes of calculating transmission expectancies by groups of insects simply because any estimate which makes 


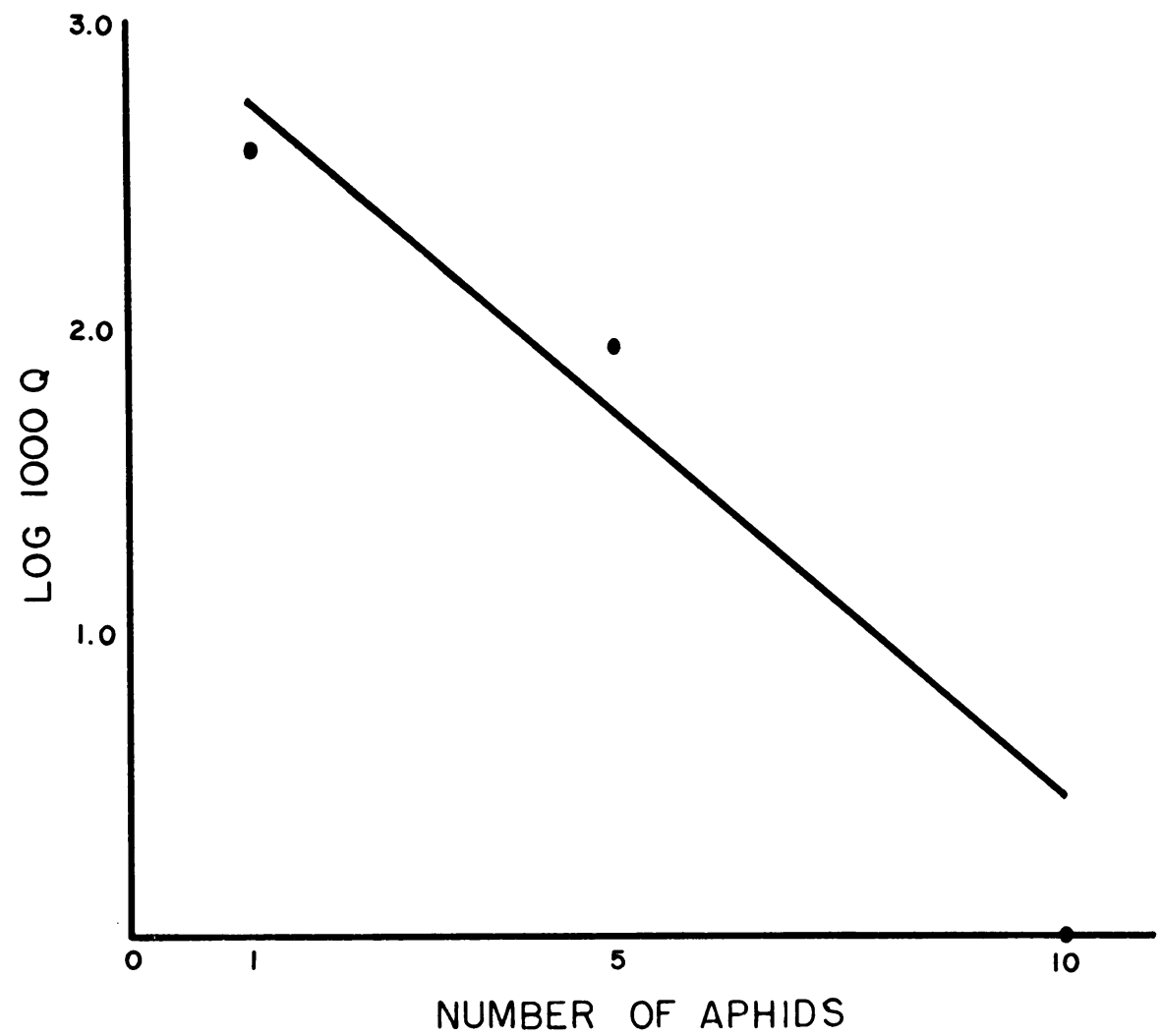

Fig. 9. Transmission results based on $\mathrm{p}^{*}{ }_{\mathrm{av}}$. (average of maximum likelihood estimates of $p$ for 1 and 5 aphids per plant), and points of observed values from the data in table 14 . The point on the $\mathrm{X}$ axis represents $\mathrm{Q}=0.0000$.

use of all the available information is preferred. $A$ weighted average of $p^{*}$ $\left(\mathrm{p}^{*}{ }_{\mathrm{w} \text {.av. }}\right)$ obtained by multiplying each value of $\mathrm{p}^{*}$ with number of insects comprising the group, adding these products and dividing by the total number of insects involved, may be an even better estimate. Transmission expectancies for 1,5 , and 10 aphids per plant were obtained using four different estimates of $\mathrm{p}\left(\mathrm{p}, \mathrm{p}^{*}{ }_{\mathrm{av} .}, \mathrm{p}^{*}{ }_{\mathrm{w} . \mathrm{av} .}, \mathrm{p}^{* *}\right)$ based upon the data given in table 12, and are plotted in figure 7 (the logarithms of values of $Q=1-P$ have been used in the graph to linearize). It may be seen that the curves obtained using $p^{*}$ - a mere average, or a weighted average-showed far better fit to observed points than using $p$ ( $\mathrm{P}_{\text {obs. }}$ for single insects $)$, or $\mathrm{p}^{* *}$ (the estimate obtained using the third method above). Actually the curve resulting from $\mathrm{p}^{*}{ }_{\mathrm{w} \text {. av. }}$ seems to give the best approximation to observed values.

Average $\mathrm{p}^{*}\left(\mathrm{p}^{*}{ }_{\mathrm{av}}\right.$. $)$ was used to compute transmission expectancies for groups of insects in different experiments. Figures 8 and 9 show that observed results for 1,5 , and 10 aphids per plant during a long inoculation access of 48 hours (from tables 11 and 14, respectively) were well balanced around the curves for calculated expectancies. Curves for the results for 1, 2, 


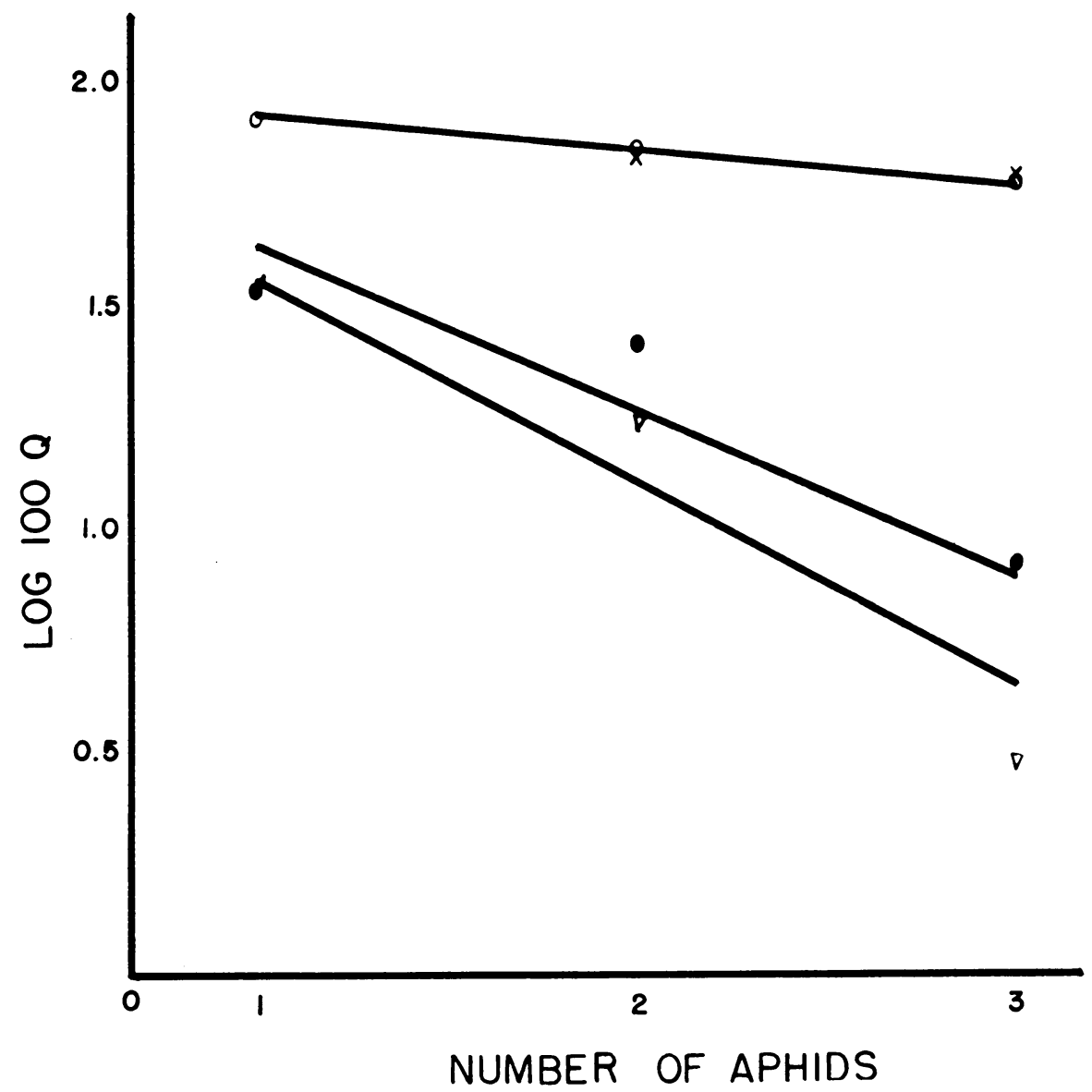

Fig. 10. Transmission results based on $\mathrm{p}^{*}$ av. (average of maximum likelihood estimates of $\mathrm{p}$ for 1, 2, and 3 aphids per plant), and points of observed values using 5 hours (upper curve, $o$ and $x$ represent points for 2 and 3 aphids confined individually and together, respectively) and $60 \pm 2$ minutes (middle and lower curves - middle curve for groups of 2 and 3 aphids confined individually; lower curve for groups of 2 and 3 aphids confined together: the points for the two lines are represented by o and $v$, respectively) of inoculation access period (data from tables 8 and 10 ).

and 3 aphids (fig. 10), individuals of groups of 2 and 3 confined singly or in groups, fit well to points of observed values (from tables 8 and 10) in both experiments using five hours, and $60 \pm 2$ minutes' long inoculation access periods. In fact, in the latter case the evidence for a difference between the expected and observed values was lacking (chi squares using transmissions by 2 and 3 aphids singly, in groups, and average of singly and groups were 0.15 , 0.843 , and $0.604 ;$ d. f. $=1 ; p=>0.70,>0.30$, and $>0.30$, respectively). In case of $1,2,3,4$, and 5 aphids per plant given $30 \pm 1$ minutes of inoculation access period (fig. 11) again, observed values (from table 13) were in close 


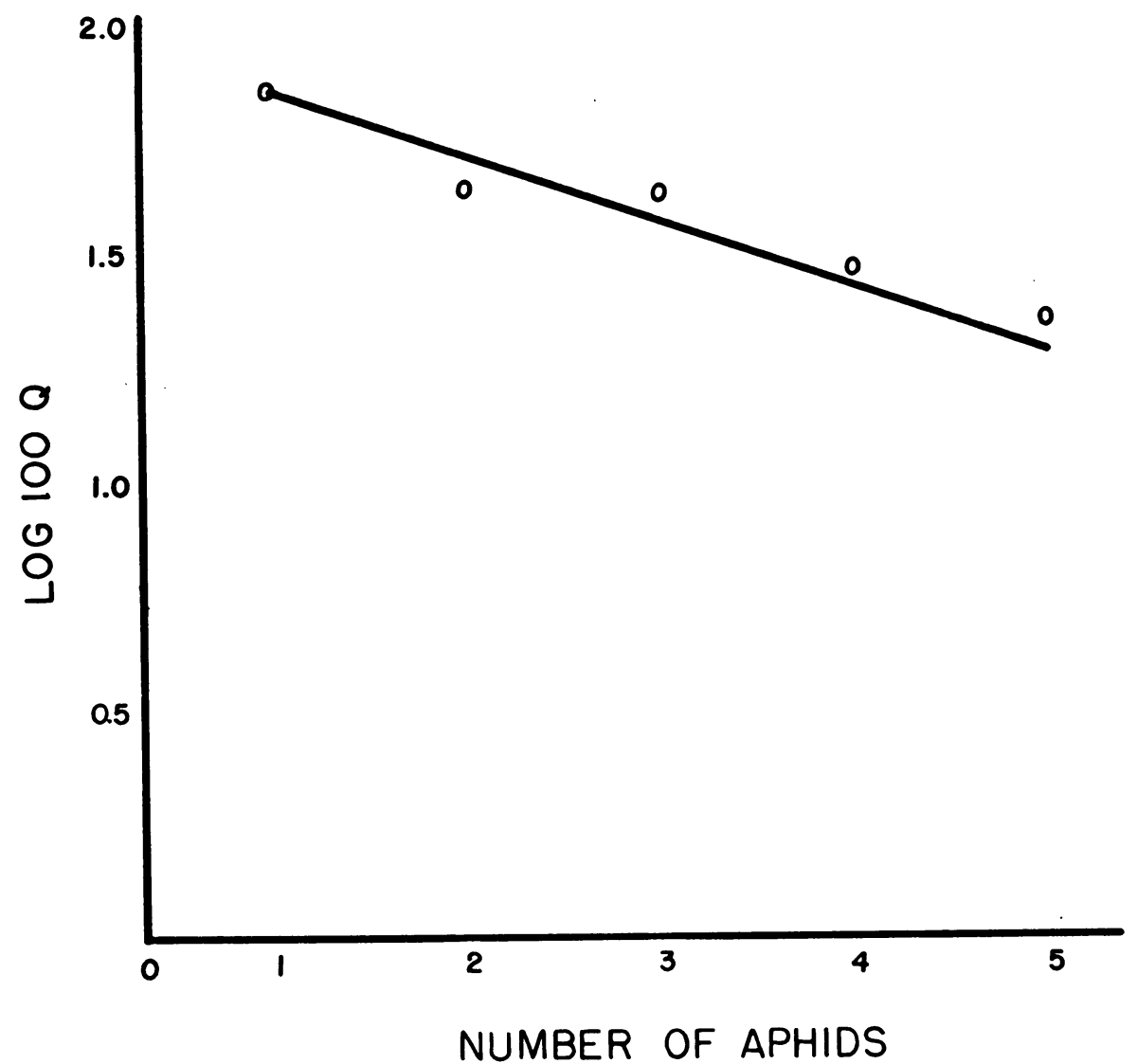

Fig. 11. Transmission results based on $\mathrm{p}^{*}{ }_{\text {av. }}$ (average of maximum likelihood estimates of $\mathrm{p}$ for $1,2,3,4$, and 5 aphids per plant), and points of observed values in transmission of potato leafroll virus by $M$. persicae given $30 \pm 1$ minutes of inoculation access period (based on table 13).

agreement with calculated values and there was no evidence for difference $\left(\chi^{2}=3.419\right.$, d. f. $\left.=3, p=>0.30\right)$.

Thus, in case of both short and long $(30 \pm 1$ min., $60 \pm 2$ min., five hours, and two days) inoculation access periods the actual values of transmission were in accordance with the values expected under binomial assumptions when a maximum likelihood estimator was used to evaluate $p$. This lends further support to Watson's (1936) hypothesis that transmission by individuals in a colony is an independent event, and it negates any 'mass-action' effect.

On the other hand, Kirkpatrick and Ross (1952) reported that in case of potato leafroll virus and Physalis angulata, transmission during a long access period resulted in observed values for groups of 5 and 10 Myzus persicae per plant which were consistently less than expected under the binomial as- 
TABLE 23

TRANSMISSION OF POTATO LEAFROLL VIRUS TO PHYSALIS ANGULATA BY 1, 5, AND $10 M Y Z U S$ PERSICAE PER PLANT (FROM KIRKPATRICK AND ROSS, 1952)

\begin{tabular}{|c|c|c|c|c|c|c|c|}
\hline \multirow{3}{*}{ Trial number } & \multirow{3}{*}{$\begin{array}{l}\text { Inocu- } \\
\text { lation } \\
\text { access } \\
\text { (hours) }\end{array}$} & \multirow{3}{*}{$\begin{array}{c}\text { Number } \\
\text { of } \\
\text { aphids }\end{array}$} & \multirow{3}{*}{$\mathrm{p}^{*} \dagger$} & \multicolumn{4}{|c|}{ Probability of transmission } \\
\hline & & & & \multirow{2}{*}{ Ohserved } & \multicolumn{3}{|c|}{ Expected using } \\
\hline & & & & & $p^{*}$ & $p^{*}$ uv. $\neq$ & $\mathrm{p}^{*}{ }_{\mathrm{w} . \mathrm{av} . \S} \S$ \\
\hline \multirow{3}{*}{1} & \multirow{3}{*}{144} & 1 & 0.450 & 0.450 & 0.450 & 0.2897 & 0.2231 \\
\hline & & 5 & 0.214 & 0.700 & 0.950 & 0.8153 & 0.7170 \\
\hline & & 10 & 0.205 & 0.900 & 0.998 & 0.9659 & 0.9199 \\
\hline \multirow{3}{*}{2} & \multirow{3}{*}{144} & 1 & 0.360 & 0.360 & 0.360 & 0.2843 & 0.2362 \\
\hline & & 5 & 0.302 & 0.840 & 0.893 & 0.8123 & 0.7400 \\
\hline & & 10 & 0.191 & 0.880 & 0.989 & 0.9648 & 0.9324 \\
\hline \multirow{3}{*}{3} & \multirow{3}{*}{144} & 1 & 0.425 & 0.425 & 0.425 & 0.2747 & 0.2100 \\
\hline & & 5 & 0.211 & 0.675 & 0.937 & 0.7992 & 0.6923 \\
\hline & & 10 & 0.188 & 0.875 & 0.996 & 0.9597 & 0.9055 \\
\hline \multirow{3}{*}{4} & \multirow{3}{*}{120} & 1 & 0.433 & 0.433 & 0.433 & 0.2510 & 0.1968 \\
\hline & & 5 & 0.097 & 0.400 & 0.942 & 0.7643 & 0.6680 \\
\hline & & 10 & 0.223 & 0.920 & 0.997 & 0.9445 & 0.8898 \\
\hline \multirow{3}{*}{5} & \multirow{3}{*}{24} & 1 & 0.100 & 0.100 & 0.100 & 0.1020 & 0.1185 \\
\hline & & 5 & 0.048 & 0.220 & 0.410 & 0.4161 & 0.4680 \\
\hline & & 10 & 0.1576 & 0.820 & 0.651 & 0.6590 & 0.7164 \\
\hline
\end{tabular}

t When 1 insect was used, $\mathrm{p}^{*}=p=$ the observed probability of transmission by single insects, otherwise $\mathrm{p}^{*}$ was calculated using the relationship $\mathrm{p}^{*}=1-\mathrm{n} \sqrt{\mathrm{Q}}$.

$\ddagger \mathrm{p}^{*} \mathrm{av}$. means average of estimates of $\mathrm{p}$ for 1,5 , and 10 insects per plant.

$\S \mathrm{p}^{*}$ w.av. means weighted average of estimates of $\mathrm{p}$ for 1,5 , and 10 insects per plant.

sumptions. To compute the expected values they used $p$ (actual transmission by single insects) and not $\mathrm{p}^{*}{ }_{\text {av. }}$ (average of $\mathrm{p}^{*}$ ) which is statistically a more appropriate estimate to use when testing whether or not the observed values are in accordance with predicted binomial expectancies. Table 23 shows that the reported gap between expected and observed values of transmission for 5 and 10 aphids per plant becomes reduced when $\mathrm{p}^{*}{ }_{\text {av. }}$ is used instead of $p$ and becomes minute when $\mathrm{p}^{*}{ }_{\mathrm{w} \text {, av. }}$ is used. In fact, in one out of four cases of transmission by 5 aphids the observed value actually exceeds that expected. However, in all cases of transmission by 10 aphids the observed value remained lower than the calculated expected one. Williams (1957, unpublished thesis) also used $p$ to obtain transmission expectancies by groups. Even so, in one of his two series of trials (Williams' table 4) the observed transmission values exceeded the transmission expectancies in two out of three trials for both 5 and 10 aphids per plant (table 24), and considering the totals, observed transmission values were in close agreement with expected ones, especially when $\mathrm{p}^{*}{ }_{\text {av }}$. was used to compute transmission expectancies. In the other series of his trials (Williams' table 3 ) observed transmission values for 5 and 10 aphids per plant did not obtain the expected levels calculated using $p$; but again when $\mathrm{p}^{*}$ av. was used (table 25) for computing transmission expectancies, for 5 aphids per plant the value of observed transmission exceeds 
TABLE 24

TRANSMISSION OF POTATO LEAFROLL VIRUS TO PHYSALIS ANGULATA

BY 1, 5, AND 10 MYZUS PERSICAE PER PLANT DURING 120 HOURS

OF INOCULATION ACCESS (FROM TABLE 4 OF WILLIAMS, 1957, UNPUBLISHED THESIS)

\begin{tabular}{|c|c|c|c|c|c|c|}
\hline \multirow{3}{*}{ Trial number } & \multirow{3}{*}{$\begin{array}{l}\text { Number of } \\
\text { aphids } \\
\text { per plant }\end{array}$} & \multirow{3}{*}{$p^{*} \dagger$} & \multicolumn{4}{|c|}{ Probability of transmission } \\
\hline & & & \multirow{2}{*}{ Observed } & \multicolumn{3}{|c|}{ Expected using } \\
\hline & & & & $p^{*}$ & $\mathrm{p}_{\mathrm{av} . \ddagger}$ & $p^{*}{ }_{\text {w.av }} \$$ \\
\hline 1 & $\begin{array}{r}1 \\
5 \\
10\end{array}$ & $\begin{array}{l}0.105 \\
0.148 \\
0.149\end{array}$ & $\begin{array}{l}0.105 \\
0.550 \\
0.800\end{array}$ & $\begin{array}{l}0.105 \\
0.426 \\
0.670\end{array}$ & $\begin{array}{l}0.1340 \\
0.5130 \\
0.7628\end{array}$ & $\begin{array}{l}\ldots \ldots \\
\ldots \ldots \\
\ldots \ldots\end{array}$ \\
\hline 2 & $\begin{array}{r}1 \\
5 \\
10\end{array}$ & $\begin{array}{l}0.100 \\
0.021 \\
0.042\end{array}$ & $\begin{array}{l}0.100 \\
0.100 \\
0.350\end{array}$ & $\begin{array}{l}0.100 \\
0.410 \\
0.651\end{array}$ & $\begin{array}{l}0.0543 \\
0.2436 \\
0.4279\end{array}$ & $\begin{array}{l}0.0391 \\
0.1789 \\
0.3260\end{array}$ \\
\hline 3 & $\begin{array}{r}1 \\
5 \\
10\end{array}$ & $\begin{array}{l}0.000 \\
0.059 \\
0.067\end{array}$ & $\begin{array}{l}0.000 \\
0.250 \\
0.500\end{array}$ & $\begin{array}{l}0.000 \\
0.000 \\
0.000\end{array}$ & $\begin{array}{l}0.042 \\
0.1931 \\
0.3489\end{array}$ & $\begin{array}{l}\ldots \ldots \\
\ldots \ldots \\
\ldots \ldots\end{array}$ \\
\hline Total & $\begin{array}{r}1 \\
5 \\
10\end{array}$ & $\begin{array}{l}0.0683 \\
0.0688 \\
0.0768\end{array}$ & $\begin{array}{l}0.0683 \\
0.3000 \\
0.5500\end{array}$ & $\begin{array}{l}0.0683 \\
0.2979 \\
0.5071\end{array}$ & $\begin{array}{l}0.07677 \\
0.3214 \\
0.5405\end{array}$ & $\begin{array}{l}\ldots \ldots \\
\ldots \ldots \\
\ldots \ldots\end{array}$ \\
\hline
\end{tabular}

$\dagger$ When one insect was used, $\mathrm{p}^{*}=p=$ the observed probability of transmission by single insects, otherwise $p^{*}$ was calculated using the relationship $\mathrm{p}^{*}=1-{ }^{n} \sqrt{ } \mathrm{Q}$.

$\ddagger p^{*}$ av. means a verage of estimates of $p$ for 1,5 , and 10 insects per plant.

$\$ \mathrm{p}^{*} \mathrm{w}$.av. means weighted average of estimates of $\mathrm{p}$ for 1,5 , and 10 insects per plant.

or becomes equal to expected transmission value in all the four trials and in the totals; and in the case of 10 aphids the gap between observed and expected values became less.

Furthermore, table 25 shows that $\mathrm{p}^{*}$ (the maximum likelihood estimate of $\mathrm{p}$ ) from groups of 5 and 10 insects per plant was greater than $p$ or nearly equal to it in three out of eight such possible comparisons in the first series (table 3 of Williams', 1957: unpublished thesis) and in four out of six cases both for 24 and 120 hours of inoculation access periods in the second series of trials (table 25; and table 4 of Williams, 1957: unpublished thesis). In case of Kirkpatrick and Ross (1952) also the reduction in the estimate of $p$ was not consistent with increase in numbers of aphids from 5 to 10 even under long inoculation access conditions (table 23).

Estimates of $\mathrm{p}$ for different experiments have been presented in table 26 . The value of $\mathrm{p}^{*}$ was lower than $p$ in three cases (estimates no. 1 to 3 ). This may be explained as being due to bias in computing $\mathrm{p}^{*}$ when $p$ and $\mathrm{n}$ are high (Gibbs and Gower, 1960). In the remaining six cases in which either $p$ was low or $n$ was small or both, the bias in obtaining $\mathrm{p}^{*}$ was small. Consequently there was no consistent decrease in $\mathrm{p}^{*}$ with increase in number of insects per plant $(n)$. It may be pointed out that in four out of these six cases $p^{*}$ for $\mathrm{n}=2$ was larger than $p$. This may be due to a low bias and due to the standard error of $\mathrm{p}^{*}$ for $\mathrm{n}=2$ being generally lower than that for simple binomial sampling (i.e., where $n=1$ ) as pointed out by Gibbs and Gower (1960). 
TABLE 25

TRANSMISSION OF POTATO LEAFROLL VIRUS TO PHYSALIS ANGULATA BY 1, 5, AND 10 MYZUS PERSICAE PER PLANT DURING 120 HOURS OF INOCULATION ACCESS (FROM TABLE 3 OF WILLIAMS, 1957, UNPUBLISHED THESIS)

\begin{tabular}{|c|c|c|c|c|c|c|}
\hline \multirow{3}{*}{ Trial number } & \multirow{3}{*}{$\begin{array}{l}\text { Number of } \\
\text { aphids } \\
\text { per plant }\end{array}$} & \multirow{3}{*}{$p^{*} \dagger$} & \multicolumn{4}{|c|}{ Probability of transmission } \\
\hline & & & \multirow{2}{*}{ Observed } & \multicolumn{3}{|c|}{ Expected using } \\
\hline & & & & $p^{*}$ & $\mathrm{p}_{\mathrm{av} . \ddagger}$ & $p^{*}$ w.av. $\delta$ \\
\hline 1 & $\begin{array}{r}1 \\
5 \\
10\end{array}$ & $\begin{array}{l}0.050 \\
0.032 \\
0.022\end{array}$ & $\begin{array}{l}0.050 \\
0.150 \\
0.200\end{array}$ & $\begin{array}{l}0.050 \\
0.226 \\
0.401\end{array}$ & $\begin{array}{l}0.0347 \\
0.1619 \\
0.2976\end{array}$ & $\begin{array}{l}0.0269 \\
0.1276 \\
0.2486\end{array}$ \\
\hline 2 & $\begin{array}{r}1 \\
5 \\
10\end{array}$ & $\begin{array}{l}0.100 \\
0.070 \\
0.058\end{array}$ & $\begin{array}{l}0.100 \\
0.316 \\
0.450\end{array}$ & $\begin{array}{l}0.100 \\
0.410 \\
0.651\end{array}$ & $\begin{array}{l}0.0760 \\
0.3265 \\
0.5464\end{array}$ & $\begin{array}{l}0.0644 \\
0.2831 \\
0.4861\end{array}$ \\
\hline 3 & $\begin{array}{r}1 \\
5 \\
10\end{array}$ & $\begin{array}{l}0.050 \\
0.044 \\
0.028\end{array}$ & $\begin{array}{l}0.050 \\
0.200 \\
0.250\end{array}$ & $\begin{array}{l}0.050 \\
0.226 \\
0.401\end{array}$ & $\begin{array}{l}0.0407 \\
0.1876 \\
0.3400\end{array}$ & $\begin{array}{l}0.0344 \\
0.1605 \\
0.2953\end{array}$ \\
\hline 4 & $\begin{array}{r}1 \\
5 \\
10\end{array}$ & $\begin{array}{l}0.100 \\
0.214 \\
0.095\end{array}$ & $\begin{array}{l}0.100 \\
0.700 \\
0.632\end{array}$ & $\begin{array}{l}0.100 \\
0.410 \\
0.651\end{array}$ & $\begin{array}{l}0.1363 \\
0.5194 \\
0.7690\end{array}$ & $\begin{array}{l}0.1325 \\
0.5087 \\
0.7586\end{array}$ \\
\hline Total & $\begin{array}{r}1 \\
5 \\
10\end{array}$ & $\begin{array}{l}0.0750 \\
0.0703 \\
0.0466\end{array}$ & $\begin{array}{l}0.0750 \\
0.3418 \\
0.3797\end{array}$ & $\begin{array}{l}0.0750 \\
0.3220 \\
0.5403\end{array}$ & $\begin{array}{l}0.0719 \\
0.3115 \\
0.5259\end{array}$ & $\begin{array}{l}0.0558 \\
0.2496 \\
0.4369\end{array}$ \\
\hline
\end{tabular}

† When one insect was used, $\mathrm{p}^{*}=p=$ the observed probability of transmission by single insects, otherwise $\mathrm{p}^{*}$ was calculated using the relationship $\mathrm{p}^{*}=1-\mathrm{n} \sqrt{ } \mathrm{Q}$.

$\ddagger \mathrm{p}^{*}$ av. means average of estimates of $\mathrm{p}$ for 1,5 , and 10 insects per plant.

$8 \mathrm{p}^{*}$ w.av. means weighted average of estimates of $\mathrm{p}$ for 1,5 , and 10 insects per plant.

In view of the above discussion of earlier work (Kirkpatrick and Ross, 1952; Williams and Ross, 1957; Williams, 1957: unpublished thesis) and present investigations it may be concluded that consistently verifiable evidence is lacking to support the hypothesis that the efficiency of virus transmission decreases as the number of vectors used increases. Certainly little support has been gained for the suggestion that plant susceptibility decreased during transmission by groups of insects.

\section{SUMMARY}

All or nearly all adults and late instar nymphs of Myzus persicae (Sulz.) reared or maintained for at least 12 days on Physalis floridana plants infected with potato leafroll virus were found to be inoculative when tested in serial transmission tests.

In experiments on duration of inoculation access period 100 per cent transmission occurred when 10 aphids per plant were allowed two hours' inoculation access and there was no decrease in transmission when the inoculation access period was prolonged up to seven days.

Physalis floridana test plant population was found to be relatively free of plants highly resistant or immune to systemic infection with potato leafroll 


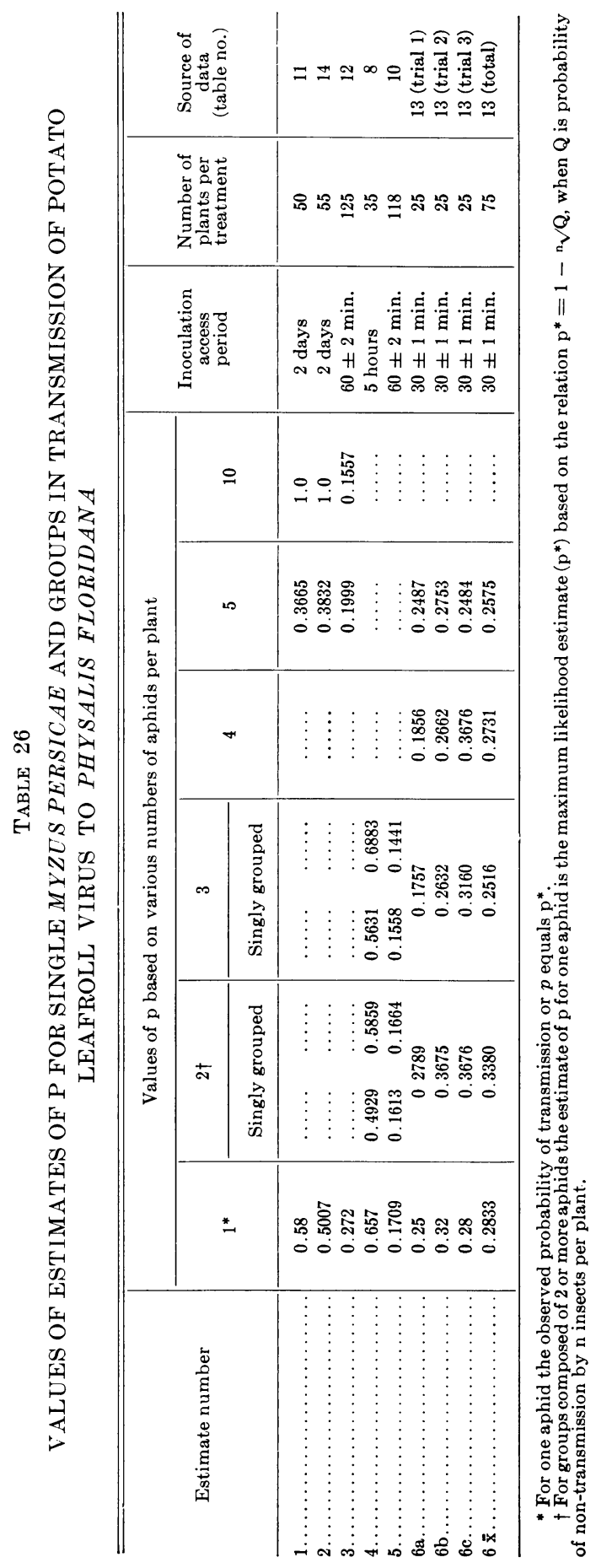


virus. Noninfection following inoculation by 5 Myzus persiscae per plant during an inoculation access of 48 hours was used as a criterion for this purpose. Partial wilting induced by withholding water for four or five days did not affect the resistance of $P$. floridana to infection with potato leafroll virus.

Using groups of 2 and 3 aphids (Myzus persicae) per plant, placed singly or confined in groups to small areas of a leaf, no evidence was obtained for interference in feeding during an inoculation access of either five hours or $60 \pm 2$ minutes even under rather crowded conditions. Confining the aphids in groups did not result in lower transmission than when the same numbers per plant were confined singly.

In experiments comparing transmission by single aphids and groups of 5 and 10 inoculative Myzus persicae during a long (two days) inoculation access period, the actual percentage transmission by groups of 5 aphids, but not 10 aphids per plant fell short of expected values of transmission calculated according to the binomial theorem using $p$ (observed probability of transmission by single aphids). Such a departure from the binomial expectancies was not observed when transmission was studied using 1,5 , and 10 aphids per plant which were allowed an inoculation access period of $60 \pm 2$ minutes, or when using $1,2,3,4$, and 5 aphids per plant and an inoculation access period of $30 \pm 1$ minutes.

Combining 9 noninoculative aphids with 1 inoculative, and 10 noninoculative aphids with 5 inoculative aphids tended to reduce the transmission success when tested during a 48 hours' access period, but grouping 4 and 5 noninoculative aphids with 1 and 5 inoculative aphids, respectively, had no such trend.

Prolonged feeding by large numbers of noninoculative Myzus persicae on Physalis floridana plants before inoculation with potato leafroll virus by single $M$. persicae using both long (two days) and short (five hours) inoculation access periods tended to decrease the probability of transmission success. However, concurrent feeding by large numbers of noninoculative $M$. persicae on the lower surface of a part of a leaf which was exposed to inoculation by single aphid on the opposite side during a seven days' long period did not result in reduced transmission.

Tests in which plants exposed to noninoculative aphids feeding for prolonged periods were inoculated (1) immediately or after some delay at end of aphid feeding, and (2) at site of aphid feeding or on a younger leaf indicated that the 'virus inhibitory effect' of feeding by Myzus persicae tended to be local and temporary. Of the other insects, viz., Myzus circumflexus (Buckton), Myzus ornatus Laing, Rhopalosiphum pseudobrassicae (Davis), and Macrosteles fascifrons Stål., tested for effect of prolonged feeding prior to inoculation, only that by $M$. circumflexus tended to reduce transmission.

The results of experiments on (1) effect of inoculation access duration, and on (2) concurrent feeding by inoculative and noninoculative Myzus persicae strongly indicated that feeding by groups of inoculative aphids during a long inoculation access could not induce the observed transmission values to be lower than expected under a hypothesis of separate and independent inoculation by vectors. 
Thus, evidence was not gained for any of the three explanatory hypotheses, viz., (1) plant resistance; (2) interference in feeding; and (3) aphid feeding considered by Kirkpatrick and Ross (1952) in their studies on potato leafroll virus, in order to explain the lower values of observed transmission by groups of 5 and 10 aphids in comparison with expected transmission values calculated using the binomial and $p$, the observed value of transmission by single Myzus persicae. That such departures from the binomial expectancy hypothesis are not consistent can be seen from an examination of Williams' (1957, unpublished thesis) and the present work, and are even less apparent when the superior estimator $\mathrm{p}^{*}$ av. (average value of the maximum likelihood estimate of $p$ ) was used.

The value of $p^{*}$ (maximum likelihood estimate of $p$ ) when $n$ (number of inoculative aphids used per plant) was 2 , was higher in some cases than when $n$ equaled 1 ; but decreased slowly with further increase in value of $n$, the decrease being rapid when $p$ was high and $n$ was larger than 4 . The results are in accordance with the properties of the maximum likelihood estimator (Gibbs and Gower, 1960) and the low values of $\mathrm{p}^{*}$ for $\mathrm{n} 5$ to 10 or larger, as compared with $p$ when $p$ is high, should not be construed as a departure from the binomial.

\section{LITERATURE CITED}

Bawden, F. C., and B. Kassanis

1946. Varietal susceptibility to potato virus Y. Ann Appl. Biol. 33:46.

Carsner, E., and C. F. LAckey

1929. Mass-action in relation to infection with special reference to curly top of sugar beet. (Abs.) Phytopath. 19:1137.

CARTER, WAlter, and C. T. Schmidt

1935. Mass action phenomena in mealybug wilt. Ent. Soc. Amer. Ann. 28(3):396-403.

Costa, A. S., and C. W. BennetT

1950. Whitefly-transmitted mosaic of Euphorbia prunifolia. Phytopath. 40(3) :266-83.

Costa, A. S., and T. J. Grant

1951. Studies on transmission of the tristeza virus by the vector, Aphis citricidus. Phytopath. 41:105-13.

Duffus, JAmes E.

1960. Radish yellows, a disease of radish, sugar-beet, and other crops. Phytopath. 50 (5) :389-94.

Er.ze, D. L.

1927. De verspreiding van virusziekten van de aardappel (Solanum tubcrosum L.) door insekten. Meded. v. d. Landbouwhoogeschool, Wageningen. 31:1-90.

Frfitag, J. H.

1956. Beetle transmission, host range, and properties of squash mosaic virus. Phytopath. $46(2): 73-81$.

GibBs, A. J., and J. C. Gower

1960. The use of a multiple-transfer method in plant virus transmission studies-some statistical points arising in the analysis of results. Ann. Appl. Biol. 48 (1) : 75-83.

Giddings, N. J.

1946. Mass action as a factor in curly-top-virus infection of sugar beet. Phytopath. 36 (1) :53-56.

HAMyln, BREnda M. G.

1953. Quantitative studies on the transmission of cabbage black ringspot virus by Myzus persicae (Sulz.). Ann. Appl. Biol. 40:393-402. 
HOGGAN, IsME A.

1933. Some factors involved in aphid transmission of the cucumber mosaic virus to tobacco. Jour. Agr. Res. $47: 689-704$.

Hovey, C., and R. Bonde

1948. Physalis angulata, a test plant for the potato leafroll virus. Phytopath. 38:50507.

Jensen, D. D., N. W. Frazier, and H. E. Thomas

1952. Insect transmission of yellow leafroll of peach. Jour. Econ. Ent. 45(2):335-37.

KIRKPATRICK, H. C.

1948. Indicator studies with the leafroll virus of potatoes. Amer. Potato Jour. 25: 285-90.

KIRKPatRICK, H. C., and A. F. Ross

1952. Aphid transmission of potato leafroll virus to solanaceous species. Phytopath. 42:540-46.

KvfČALA, BOHUMf́r

1947. Studies on the relationship between some aphides and the sugar beet mosaic virus (Beta virus 2 ). Sborn. vys. školy Zeměděl., Brné, Sign. C38:1-43.

1948. Studies on the composite nature of cauliflower mosaic with a special regard to the selective transmission of both viruses in this complex disease by certain aphids. (Résumé in English). Sborn. vys. školy Zeměděl., Brné, Sign. C40:1-87.

LAIRD, E. F., JR., and R. C. DickSON

1959. Insect transmission of leaf-crumple virus of cotton. Phytopath. 49(6):324-27.

LARSON, R. H.

1945. Resistance in potato varieties to yellow dwarf. Jour. Agr. Res. 71:441-51.

LOCKE, S. B.

1954. Vector feeding relative to resistance in potato varieties. (Abs.) Amer. Potato Jour. $31: 370$.

MACCARTHY, H. R.

1954. Aphid transmission of potato leafroll virus. Phytopath. 44:167-74.

ORLANDO, A., and K. SilberschmidT

1946. Estudos sobre a disseminação natural do virus da "clorose infeciosa" das malvaceas (Abutilon Virus I Baur) e a sua relação com o inseto-vector "Bemesia tabaci (Genn.)" (Homoptera: Aleyrodidae). Arquivos do Instituto Biológico, São Paulo, 17:1-36.

Pontis Videla, R. E.

1953. Las virosis la lechoza (Carica papaya L.) en Venezuela. I. Transmission del "mosaico." Agron. Trop. 2(4) :241-51.

Posnette, A. F., and N. F. Robertson

1950. Virus diseases of cacao in west Africa. VI. Vector Investigations. Ann. Appl. Biol. 37(3) :363-77.

Semal, J.

1955. Quelques transmissions par pucerons de Cucumis virus I Doolittle à partir de dahlia. Parasitica 11(4):118-23.

Severin, H. H. P.

1931. Modes of curly-top transmission by the beet-leafhopper, Eutettix tenncllus (Baker). Hilgardia 6(8):254-76.

SEverin, H. H. P., and R. M. DRAKE

1948. Sugar beet mosaic. Hilgardia 18(13):483-521.

Severin, H. H. P., and C. M. ToMpkins

1950. Aphid transmission of mosaic virus and symptoms of other virus diseases of Primula obconica. Hilgardia 20 (15) :279-98.

SHEFFIELD, F. M. L.

1957. Virus diseases of sweet potato in east Africa. I. Identification of the viruses and their insect vectors. Phytopath. 47(10):582-90.

Simpson, G. W., and W. A. Shands

1949. Progress on some important insects and disease problems of Irish potato production in Maine. Maine Agr. Expt. Sta. Bul. 470:1-50. 
SKotland, C. B.

1953. Aphid transmission of the Wisconsin pea streak virus. (Abs.) Phytopath. 43 (9) : 484 .

SмIтH, K. M.

1929. Studies on potato virus diseases. V. Insect transmission of potato leafroll. Ann. Appl. Biol. 16:209-29.

STOREY, H. H.

1938. Investigations of the mechanism of the transmission of plant viruses by insects. II. The part played by puncture in transmission. Roy. Soc. London, Proc., Ser. B. $125: 455-77$.

StOREY, H. H., and A. K. RYLAND

1955. Transmission of groundnut rosette virus. Ann. Appl. Biol. 43(3):423-32.

STUBBS, L. L.

1952. Further host range and transmission studies with a virus disease of carrot endemic in Australia. Australian Jour. Sci. Res. B. 5(4) :399-408.

SYlvester, E. S.

1954. Aphid transmission of non-persistent plant viruses with special reference to the Brassica nigra virus. Hilgardia 23(3):53-95.

1955. Lettuce mosaic virus transmission by the green peach aphid. Phytopath. 45: 357-70.

1956. Beet yellows virus transmission by the green peach aphid. Jour. Econ. Ent. 49: $789-800$.

VARMA, P. M.

1952. Studies on the relationship of the Bhendi yellow vein-mosaic virus and its vector, the white fly (Bemesia tabaci Gen.). Indian Jour. Agr. Sci. 22:75-91.

WAGgoner, P. E., and J. B. KRING

1956. Use of shade tent and insecticides in studies of virus spread. Phytopath. 46(10): 562-63.

Watson, M. A.

1936. Factors affecting the amount of infection obtained by aphis transmission of the virus $H y$. III. Roy. Soc. London, Phil. Trans., Ser. B. 226:457-89.

1946. The transmission of beet mosaic and beet yellows virus by aphides; a comparative study of a non-persistent and a persistent virus having host plant and vector in common. Roy. Soc. London, Proc., Ser. B. 133:200-19.

Wat'son, M. A., R. Hull, J. W. Blencowe, and B. M. G. Hamyln

1951. The spread of beet yellows and mosaic virus in the sugar-beet root crop. I. Field observations on the virus diseases of sugar-beet and their vectors Myzus persicae (Sulz.) and Aphis fabae Koch. Ann. Appl. Biol. 38:743-64.

WATson, M. A., and F. M. RoBerts

1939. A comparative study of the transmission of Hyoscyamus virus 3 , potato virus $\mathrm{Y}$, and cucumber virus I by the vectors Myzus persicae (Sulz.), M. circumflexus (Buckton) and Macrosiphum gei (Koch). Roy. Soc. London, Proc., Ser. B. 127: 543-76.

Williams, W. L.

1957. Experiments on the transmission of potato leafroll virus. Unpublished Ph.D. thesis of Cornell University, Ithaca, N.Y.

Williams, W. L., and A. F. Ross

1957. Aphid (Myzus persicae) transmission of potato leafroll virus as affected by feeding of non-viruliferous aphids on the test plants and by vector variability. (Abs.) Phytopath. 47(9):538. 

The journal Hilgardia is published at irregular intervals, in volumes of about 600 pages. The number of issues per volume varies.

Subscriptions are not sold. The periodical is sent as published only to libraries, or to institutions in foreign countries having publications to offer in exchange.

You may obtain a single copy of any issue free, as long as the supply lasts; please request by volume and issue number from:

\section{Agricultural Publications \\ 207 University Hall \\ 2200 University Avenue \\ Berkeley 4, California}

The limit to nonresidents of California is 10 separate issues on a single order. A list of the issues still available will be sent on request. 


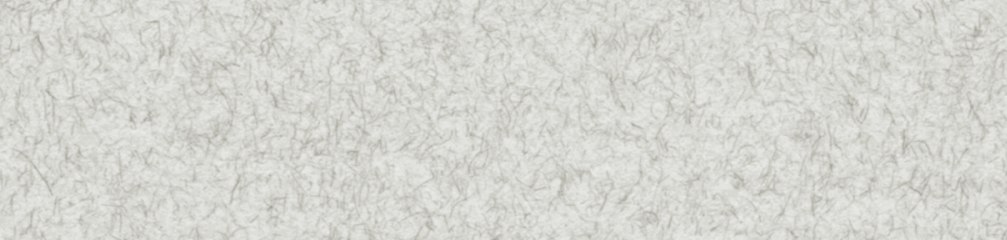

act 3

x. $+4=1,2$

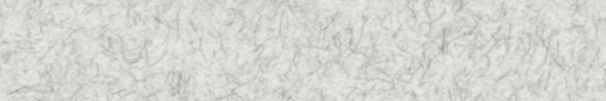

